\title{
The Hardness of Additively Manufactured Alloys
}

\author{
J.S. Zuback and T. DebRoy * \\ Department of Materials Science and Engineering, The Pennsylvania State University, \\ University Park, PA 16802, USA; jsz125@psu.edu \\ * Correspondence: debroy@psu.edu
}

Received: 4 October 2018; Accepted: 17 October 2018; Published: 23 October 2018

\begin{abstract}
The rapidly evolving field of additive manufacturing requires a periodic assessment of the progress made in understanding the properties of metallic components. Although extensive research has been undertaken by many investigators, the data on properties such as hardness from individual publications are often fragmented. When these published data are critically reviewed, several important insights that cannot be obtained from individual papers become apparent. We examine the role of cooling rate, microstructure, alloy composition and post process heat treatment on the hardness of additively manufactured aluminum, nickel, titanium and iron base components. Hardness data for steels and aluminum alloys processed by additive manufacturing and welding are compared to understand the relative roles of manufacturing processes. Furthermore, the findings are useful to determine if a target hardness is easily attainable either by adjusting AM process variables or through appropriate alloy selection.
\end{abstract}

Keywords: additive manufacturing; microstructure; hardness; mechanical properties; aluminum alloys; Steels; nickel alloys; titanium alloys

\section{Introduction}

Additive manufacturing (AM) involves the layer-by-layer deposition of alloys from powder or wire feedstock by rapid heating, melting, solidification and cooling. Evolution of microstructure and properties of the components during AM is affected by repeated thermal cycles, large temperature gradients and relatively high cooling rates during solidification and solid-state phase transformations upon cooling. Serviceability of additively manufactured components depend on their chemical composition, microstructure, properties and defects. Hardness is one of the most commonly tested mechanical properties because measurements are quick, relatively inexpensive and provide insight to other properties such as yield strength [1] and wear resistance [2]. Literature data on some mechanical properties such as the yield strength of additively manufactured components often show significant scatter that can mostly be attributed to the presence of internal defects. In contrast, micro-hardness data are largely unaffected by internal defects. As a result, hardness measurements indicate the true effect of microstructural features such as the presence of various phases, precipitate particles, average grain size and alloy composition. For a specific alloy, these microstructural features depend on the AM processing conditions.

Much of the reported mechanical property data in the literature are for as fabricated condition without any post processing heat treatment. Understanding of the hardness data for these cases allow examination of the role of AM process variables prior to the property improvements during post processing. During AM, cooling rates between the liquids and solidus temperatures and in lower temperature ranges where important solid-state phase transformations take place are rapid. As a result, there is often insufficient time for the fabricated components to attain equilibrium microstructures. In other words, the rapid thermal cycles often limit the extent of some of the phase transformations. 
In those situations, the data from multiple sources available in the literature allow us to examine the impact of the AM variables on the hardness variation and assess the extent to which AM processes allow tailoring of hardness of components immediately after their fabrication. Comparing these reported variations from independent studies with the known variations of hardness owing to changes in alloy compositions through materials selection enables a practical way to select both the alloy and AM process variations to achieve a target hardness.

Many of the engineering alloys used in AM require post processing to achieve optimal properties. Much attention has been given to adjusting process variables [3,4], optimizing scanning strategies $[5,6]$, numerically calculating important metallurgical variables [7-12] and post-fabrication techniques like heat treatments or hot isostatic pressing $[13,14]$ for achieving target properties. For example, it has been observed experimentally that the AM of age-hardenable alloys, which rely on the presence of small precipitates for strength and hardness, often require post-processing heat treatments that allow time for precipitation to achieve properties similar to those found in conventional processes [15]. For these alloys, heat treatment produces significant changes in microstructure and properties for a given composition of an alloy.

Although the serviceability of the components produced by AM depend on their microstructure and mechanical properties, the available data are fragmented in many individual publications. After only about a quarter of a century of research, there have been many influential research articles and critical reviews [16-28] addressing the scientific and technological advancements in the AM of metals. Moreover, several reviews have focused on mechanical properties [29-32], microstructures [30,33,34] and specific AM processes [35-40] and alloy systems [29,31,38,41-44]. A periodic assessment of the links between processing, microstructure and properties is needed to advance our understanding as AM is still a relatively new and rapidly developing fabrication method. This review provides a compilation of the available hardness data for AM components for widely used alloys in order to seek reusable insights and make conclusions that cannot be made from individual papers. These data allow us to examine the hardness variations from various AM processes characterized by different cooling rates and processing conditions.

Here we examine the role of metallurgical variables like cooling rate, microstructure, alloy composition and post-processing heat treatments on the hardness of multiple alloy components fabricated by AM. The data reviewed allow us to examine the role of AM process variants on the microstructure and component hardness prior to post processing heat treatment. In many papers, hardness values are reported without any microstructural characterization precluding any direct correlation between microstructure and hardness. In those cases, selection of an effective compositional variable allows examination of the role of important alloying elements on hardness. While such correlations cannot take advantage of the decades of research correlating microstructure with properties, they reveal several immensely useful insights. Furthermore, the findings discussed are useful to determine if a target hardness is attainable either by adjusting AM process variables or selection of an appropriate alloy composition. Finally, they serve as a basis for alloy selection for attaining a target hardness of a component fabricated by AM.

\section{Influence of Process Variables}

AM processes generally fall into two main categories depending on the delivery method of the feedstock material. Powder bed fusion (PBF) consists of spreading a fine layer of powder material across a substrate with a recoating blade or roller. The powder feedstock remains stationary while a heat source is scanned along predefined paths to produce the desired part in a layer-by-layer manner. In directed energy deposition (DED) AM, either powder or wire feedstock is delivered coaxially with the heat source into a molten pool. In contrast to PBF, the feedstock delivery system moves with the heat source in DED processes. Types of heat sources commonly used include lasers (L), electron beams (EB), plasma arcs (PA) and gas metal arcs (GMA). In this review, a distinction between individual studies will be made by defining the specific AM process and type of heat source. For example, a laser based 
DED process is designated as DED-L. There is a wide range of process parameter combinations used in different AM processes that determine the structure and properties of fabricated components. In this section, the influence of these variables on the hardness of AM alloys will be discussed.

\subsection{Energy Input}

The thermal histories during AM vary both spatially and temporally. Temperature measurements are limited to specific locations within the substrate when thermocouples are used and the surface of the molten pool when infrared imaging is used. Therefore, it is often difficult to represent the cooling rates and thermal histories of the entire AM process with a single value. An approximate alternative is to compare studies based on the amount of energy is delivered to the deposit in the form of a linear heat input [17]

$$
E=\frac{P}{v}
$$

where $P$ is the power of the heat source in Watts and $v$ is the scanning speed in $\mathrm{mm} / \mathrm{s}$. While more complex expressions for energy input exist in the literature, they often contain more process variables for the calculation, the details of which are not always reported.

Austenitic stainless steels, such as SS 304L and 316L and titanium alloy Ti-6Al-4V have received much attention in the AM literature. Figure 1 shows the reported Vickers hardness [45-53] for austenitic stainless steels SS 316, SS 316L and SS 304L as a function of linear heat input. Generally, a higher heat input results in large molten pools, higher peak temperatures and slower cooling rates. It is expected that hardness will decrease with increases in linear heat input due to more heat accumulation, larger grain sizes and microstructural coarsening. A slight downward trend is observed in Figure 1 when all data is collected and plotted together. It should be noted that the scatter in the data can be caused by differences in equipment and techniques from independent researchers. However, it is interesting to note the differences with slight changes in chemical composition between SS316 and SS316L. Although each stainless steel is microstructurally similar, noticeable changes in micro-hardness are observed due to slight variations in carbon concentration.

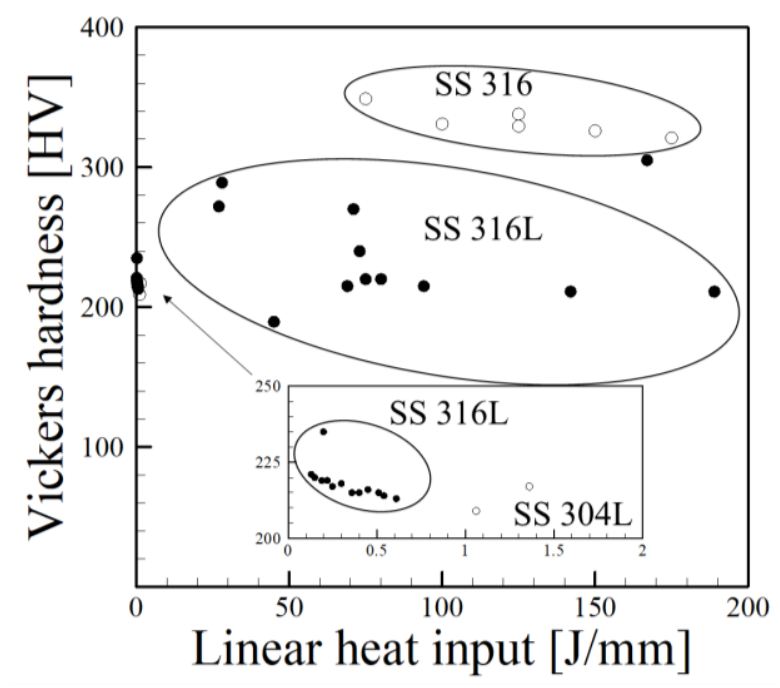

Figure 1. Hardness measurements for austenitic stainless steels deposited by AM as a function of linear heat input [45-53].

In a similar manner, average hardness values [54-65] are plotted as a function of linear heat input for Ti-base alloys in Figure 2. Small values of linear heat input typically are found in powder bed processes where low powers and high scanning speeds are used. In contrast, DED and wire-based AM processes tend to use higher powers and lower scanning speeds, contributing to higher linear heat inputs. Observed microstructures of Ti-6Al-4V builds depend on the process used and process 
variables resulting in different cooling rates. Although there have been individual studies that show decreases in hardness with increases in linear heat input for a single process, no observable trend can be seen when all data is combined. However, the highest values are recorded for low linear heat inputs, which correspond to powder bed processes.

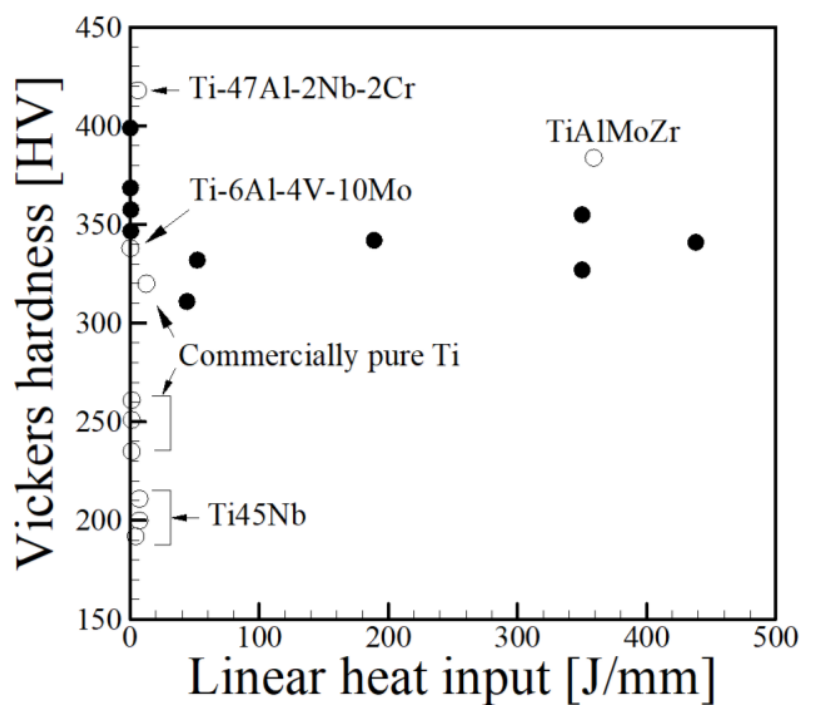

Figure 2. Vickers hardness as a function of linear heat input for titanium alloys where solid black dots correspond to Ti-6Al-4V and open points are marked otherwise [54-65].

The use of linear heat input as a process variable has also been used in many studies to determine part density or residual porosity. It is generally accepted that an increase in the density of an AM component will effectively increase hardness measurements. Indeed, multiple investigations $[52,63,66,67]$ have reported positive correlations between part density and hardness. However, it is important to note that most of these studies use a matrix of experiments where multiple process parameters are varied to optimize part density by reducing porosity. Changing process parameters that affect important metallurgical variables like cooling rates and molten pool geometry will often lead to changes in micro-hardness regardless of residual porosity. In fact, studies that contradict the correlation between part density and micro-hardness have also been reported $[54,68]$. For example, Thijs et al. [68] showed no apparent trend between part density and micro-hardness. After PBF-L of Ti-6Al-4V for a constant linear heat input of $0.21 \mathrm{~J} / \mathrm{mm}$, a sample with $99.6 \%$ density exhibited a Vickers hardness of $409 \mathrm{HV}$ while a value of $426 \mathrm{HV}$ was measured for a sample with approximately $96 \%$ density. These changes in micro-hardness were caused by a difference in hatch spacing that ultimately affects cooling rates and resulting microstructure.

The heat input for a given set of process conditions can be linked to the cooling rate. Larger heat inputs generally result in slower cooling rates due to the large molten pool sizes and higher peak temperatures. Mukherjee et al. [69] used a 3D heat transfer and fluid flow model to show that the computed cooling rates have an inverse relationship with a dimensionless heat input, that is, low heat inputs yield high cooling rates and vice versa. The dimensionless parameter is similar to Equation (1) and was defined as $Q^{*}=(P / v) /\left(P_{R} / v_{R}\right)$ where $P$ and $v$ are the laser power and scanning speed, respectively. The terms $P_{R}$ and $v_{R}$ represent the reference power and scanning speed taken to be the those that give the lowest heat input for the analyzed data set, making $Q^{*}$ always greater than unity. The computed cooling rates were validated with experimental data from Amine et al. [70] for the multilayer DED-L of SS316L as shown in Figure 3a. The calculations were then further extended to show the relationship between heat input and cooling rates for other common AM alloys in Figure $3 \mathrm{~b}$ under typical processing conditions. For all cases, similar downward trends of cooling rates are observed for higher non-dimensional heat inputs. 

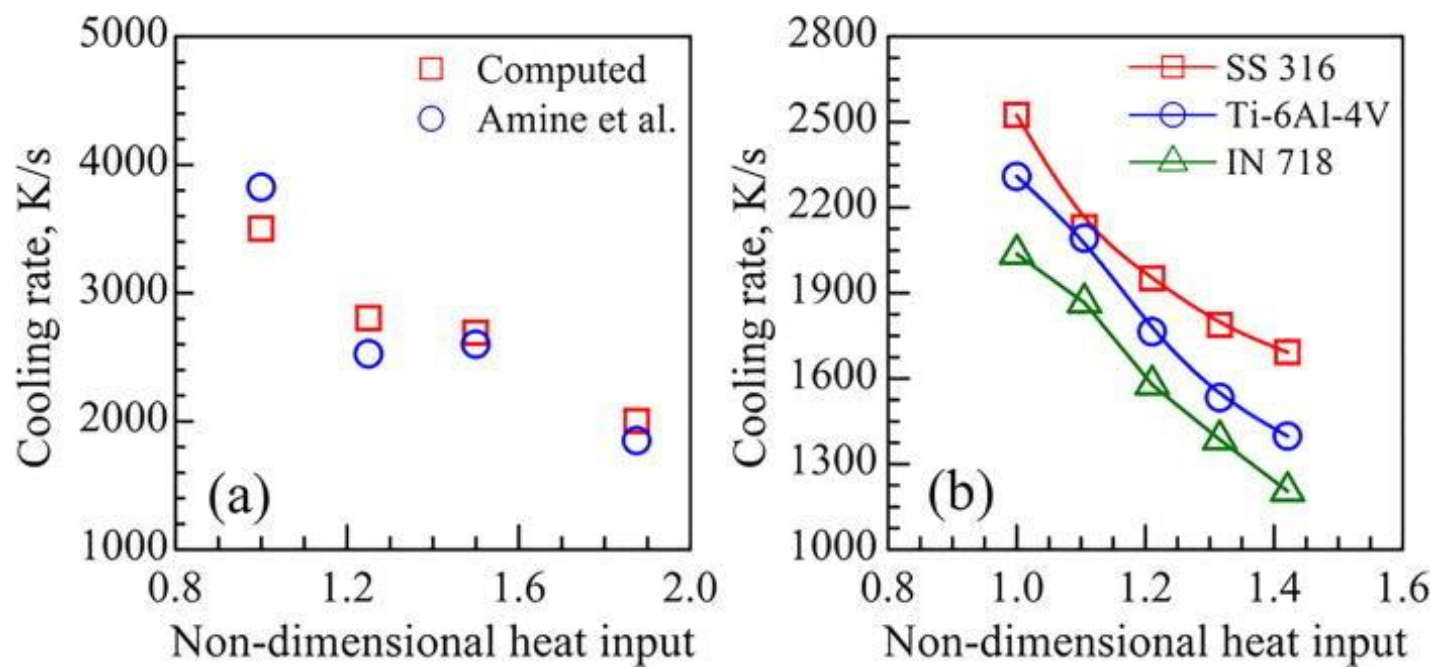

Figure 3. The relationship between computed cooling rates and a dimensionless heat input parameter for the DED-L of (a) SS316L validated from experimental data [70] and (b) common AM alloys under typical process conditions [69]. Reprinted from [69] with permission from AIP Publishing.

\subsection{Cooling Rates}

In conventional metals processing, desired microstructures and properties are achieved through precise control of cooling rates and subsequent heat treatments. The controlled cooling rates of bulk materials are approximately spatially uniform and lead to repeatability in microstructure and properties for an alloy of a given chemical composition. For this reason, useful correlations can be developed that directly relate the micro-hardness of an alloy to cooling rate. Figure $4 a-c$ shows such relationships between hardness and cooling rates for collected data on steels [71-76], aluminum alloys [77-81] and nickel alloys [82-86] in which plates or bars are cooled at controllable rates. The logarithmic scale on the horizontal axis shows that the cooling rates cover multiple orders of magnitudes. For each of the alloy classes, similar symbols indicate alloys of the same composition. Moving from left to right on the plot for a single composition indicates a change in hardness for an alloy due to an increasing cooling rate whereas moving vertically along the plot for any given cooling rate compares hardness changes due to a change in composition for alloys of the same class. Also, it can be seen that in most cases hardness values tend to plateau at high cooling rates for all alloy systems considered. 


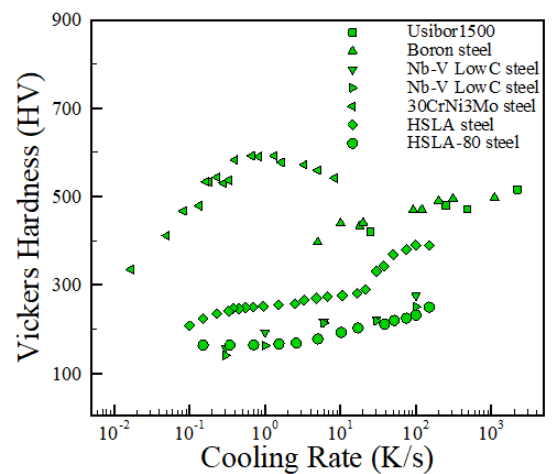

(a)

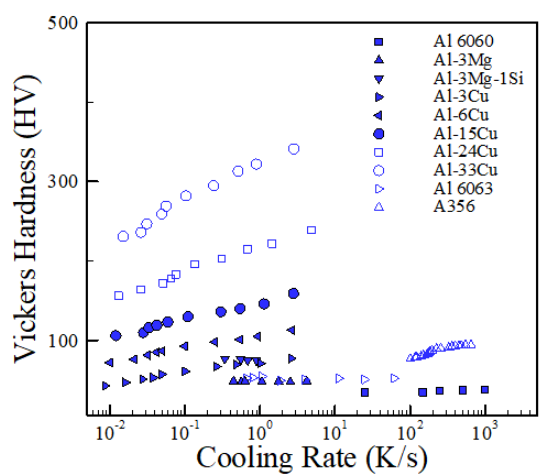

(b)

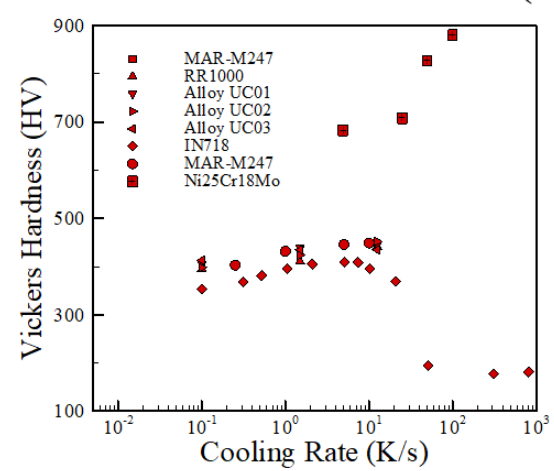

(c)

Figure 4. Hardness data as a function of reported cooling rates for (a) steels [71-76], (b) aluminum alloys [77-81] and (c) nickel alloys [82-86] in which no post-processing heat treatment was used.

From Figure $4 \mathrm{a}-\mathrm{c}$, it is observed that hardness differences resulting from changes in cooling rates are greatly outweighed by those when comparing alloys in the same class with different compositions. This trend is further supported by Figure 5 which shows hardness data for Jominy end quench samples for various grades of steel [87]. In Figure 5a, a comparison is made between different types of alloy steels with similar carbon concentrations. Similarly, Figure $5 \mathrm{~b}$ compares 8600 series steels, having small amounts of $\mathrm{Ni}, \mathrm{Cr}$ and $\mathrm{Mo}$, with varying carbon contents. In both figures, changes in hardness due to both differences in chemical composition and cooling rates is substantial. Furthermore, increases in carbon concentration represented in Figure $5 \mathrm{~b}$ can result in significant increases in hardness, regardless of cooling rate.

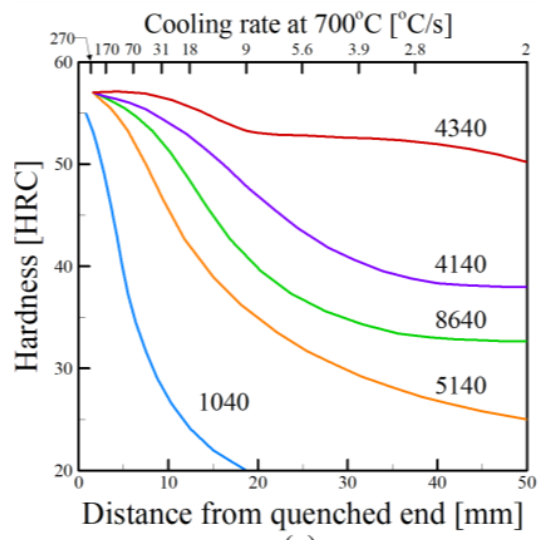

(a)

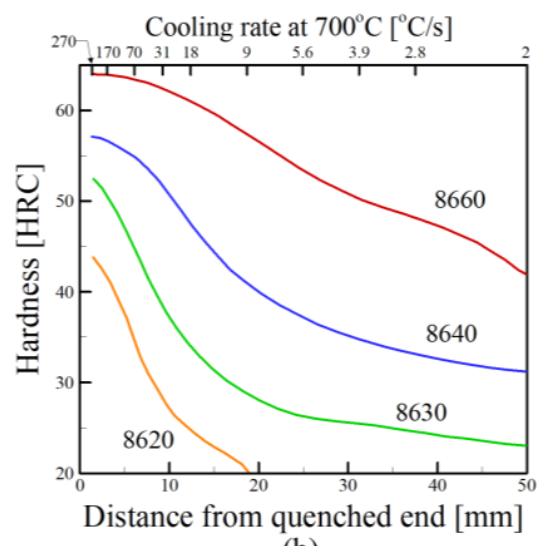

(b)

Figure 5. Hardness data for Jominy end quench experiments for (a) various steels with similar carbon concentrations and (b) 8600 series steels $(0.55 \mathrm{Ni}, 0.50 \mathrm{Cr}, 0.20 \mathrm{Mo})$ with varying carbon concentrations [87]. Reprinted from [87] with permission from Wiley. 
The thermal histories in AM involve multiple cycles of rapid heating and cooling and can span multiple orders of magnitude depending on the process and temperature range at which the cooling rate refers to. Figure 6 shows numerically computed temperature cycles from a heat transfer and fluid flow model during DED-L of SS316L for a single track, nine layer deposit [8]. Monitoring locations were selected at the midpoint in the length and width directions for selected layers. Clearly, cooling rates vary drastically both as a function of time and location within a build. For this reason, cooling rates are difficult to quantify for multi-pass, multi-layered AM parts that experience repeated heating and cooling and can make microstructural analyses convoluted.

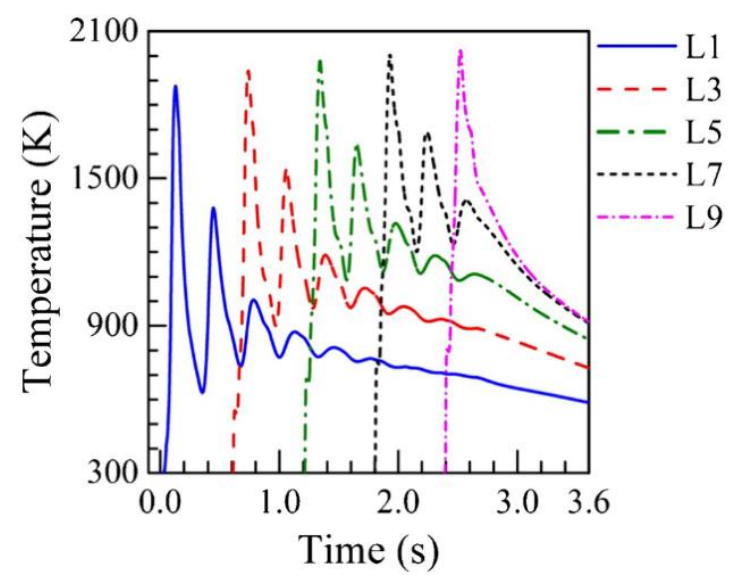

Figure 6. Computed thermal histories at the mid-length and mid-heights of selected layers during a single pass, nine layer simulation of DED-L of SS316 [8]. Reprinted from [8] with permission from Taylor \& Francis.

Both experimental and computational efforts have been undertaken for simple AM builds consisting of single passes and few layers to understand the relationship between cooling rates and micro-hardness for austenitic stainless steels. During the DED-L of SS316L [88], it was shown experimentally that the average cooling rates ranged from $22-764{ }^{\circ} \mathrm{C} / \mathrm{s}$ for different processing conditions. The corresponding Vickers hardness values measured were approximately $150 \mathrm{HV}$ for the slowest cooling rate and $368 \mathrm{HV}$ for the highest cooling rate. Although it is unclear of the temperature range at which the cooling rate was averaged, the high hardness value was attributed to the formation of martensite. Manvatkar et al. [9] combined a numerical heat transfer and fluid flow model with experiments to correlate cooling rates to micro-hardness for a single pass, three layer DED-L deposition of SS316. The calculated cooling rates, defined as the average cooling rate through the solidification temperature range, varied from approximately $7000^{\circ} \mathrm{C} / \mathrm{s}$ in the first layer to $3000{ }^{\circ} \mathrm{C} / \mathrm{s}$. The resulting measured hardness values were approximately 230 and $210 \mathrm{HV}$ for the first and third layers, respectively.

Another important process variable that is often overlooked when developing correlations is the geometry of the deposited part. The thermal history at an arbitrary location within a build will depend on the melting and solidification of material around that location. Also, the heat transfer conditions that govern the temperature history can change as different part geometries are used. Although no simple universal expressions exist to quantify the effects of geometry, a systematic study by Keist and Palmer $[1,89]$ investigated the effects of geometry on mechanical properties of Ti-6Al-4V fabricated by PBF and DED using both laser and electron beam sources. When comparing measurements between thin and thick L-shaped walls, the Vickers hardness numbers of single pass walls were significantly lower than the hardness of the 3-pass walls.

In geometries consisting of simple shapes, the hardness variations can easily be correlated with location in a build by taking multiple cross sections. In general terms, heat accumulates in a build with an increase in process time. As the build height increases further away from the substrate material, 
the heat transfer is directed through previously deposited layer which usually results in slower cooling rates. Extended times at elevated temperatures for alloys that are not precipitation hardenable causes coarsening of microstructural features, relaxation of residual stresses and dislocation motion and annihilation. As a result, hardness measurements tend to be lower at locations further away from the substrate (increasing build height) and higher in areas close to the substrate. Figure 7 shows cross sections with different orientations with respect to the build for a single pass wall of IN718 processed with DED-L. The most obvious changes in micro-hardness occur in the Z-direction as shown in Figure 7a,b, which correspond to the build direction. No significant differences were observed in the X-and Y-directions as observed in Figure 7b,c. Since IN718 is a precipitation-hardened alloy, appreciable changes in hardness at different locations in the build were attributed to aging during processing [90]. Regions near the baseplate experienced more time at high temperatures leading to enhanced precipitation.

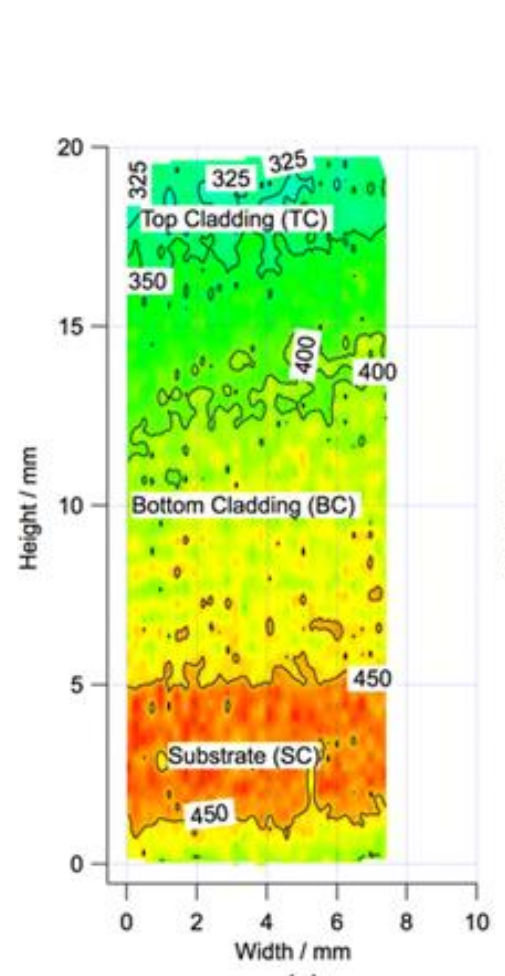

(a)

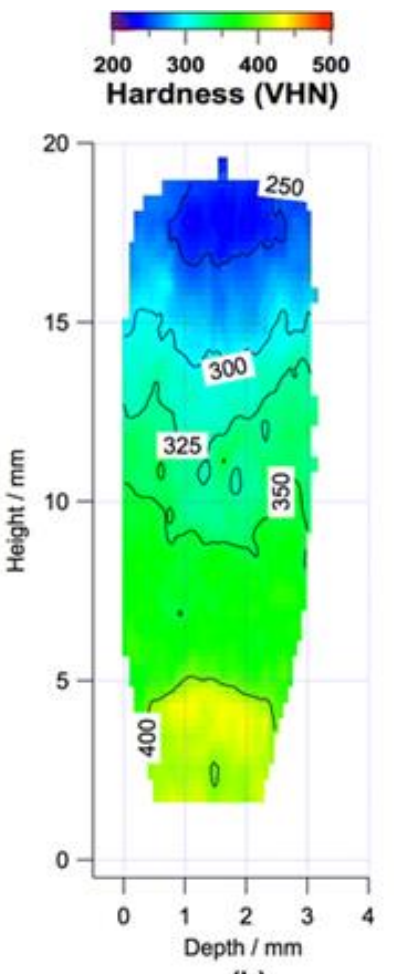

(b)

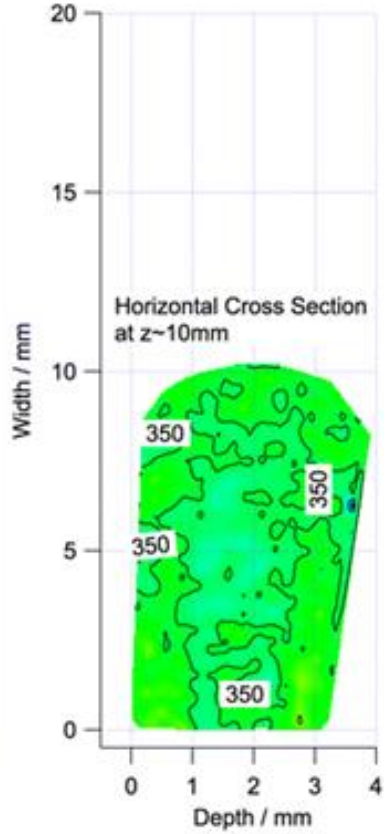

(c)

Figure 7. Hardness variations as a function of location within a DED-L single pass, multilayer build of IN718 [90] showing (a) a longitudinal cross section (X-Z plane); (b) a transverse cross section (Y-Z plane) and (c) a horizontal cross section (X-Y plane) where $X$ is the travel direction, $Y$ is the track width direction and $\mathrm{Z}$ is the build direction. Reprinted from [90] with permission from Springer Nature.

\section{Effects of Microstructure}

As-deposited microstructures of alloy components fabricated by AM are direct products of the thermal histories experienced during heating, melting, solidification and cooling. Microstructure evolution depends on alloy composition and some alloys undergo important phase transformations that can impact the properties and performance of AM parts. Table 1 shows a collection of process conditions for steels, aluminum and nickel alloys that have been fabricated by AM. Correspondingly, Table 2 shows the phases and hardness values reported for the same alloys. In this section, the influence of microstructures on the hardness of AM alloys is discussed below for various types of alloys. 
Table 1. Process parameters for iron, aluminum and nickel alloys.

\begin{tabular}{|c|c|c|c|c|c|}
\hline \multicolumn{2}{|c|}{ Alloy } & * Process & ${ }^{\dagger}$ Power (W) & $\begin{array}{c}\text { Scanning } \\
\text { Speed }(\mathrm{mm} / \mathrm{s})\end{array}$ & Ref. \\
\hline \multirow{9}{*}{ Iron Alloys } & H13 & EBM & $(20 \mathrm{~mA})$ & 500 & [91] \\
\hline & 4340 & DMD & 500 & 7.5 & [92] \\
\hline & $18 \mathrm{Ni} 300$ & SLM & $86-100$ & $180-220$ & [93] \\
\hline & H13 & DMD & $1000-1400$ & $10.5-19.0$ & [94] \\
\hline & H13 & DMD & 2500 & 5 & [95] \\
\hline & ER70S-6 & 3D GMAW & $(14-16 \mathrm{~V}, 65-76 \mathrm{~A})$ & 5.23 & [96] \\
\hline & M2 steel & DMLS & 200 & 50-175 & [97] \\
\hline & Tool steel & SLM & $75-175$ & $300-450$ & [98] \\
\hline & $420 \mathrm{SS}$ & DMLS & 283-317 & $600-1000$ & [99] \\
\hline \multirow{9}{*}{$\begin{array}{l}\text { Aluminum } \\
\text { Alloys }\end{array}$} & $\mathrm{Al} 2139$ & $\mathrm{EBF}^{3}$ & 1350 & 8.47 & [100] \\
\hline & AlSi10Mg & SLM & 195 & 800 & [101] \\
\hline & $\mathrm{Al}-12 \mathrm{Si}$ & Pulsed SLM & $500-4500$ & $1.5-3.0$ & [102] \\
\hline & $\mathrm{Al}-12 \mathrm{Si}$ & SLM & 200 & $37-2000$ & [103] \\
\hline & AlSi10Mg & SLM & 200 & 318 & [104] \\
\hline & AlSi10Mg & SLM & 200 & Not reported & [105] \\
\hline & AlSi10Mg & DMLS & 120 & 900 & [106] \\
\hline & $\mathrm{Al}-12 \mathrm{Si}$ & SLS & 100-200 & $80-200$ & [107] \\
\hline & $\mathrm{Al} 2024$ & SLM & 200 & $83-333$ & [108] \\
\hline \multirow{19}{*}{ Nickel Alloys } & IN718 & SLM & 200 & $800-1200$ & [109] \\
\hline & IN718 & DMD & 750 & 6.25 & [110] \\
\hline & IN718 & SLM & $110-130$ & $400-600$ & [67] \\
\hline & Rene 142 & EBM & Not reported & Not reported & [111] \\
\hline & Colmonoy 6 & LRM & 2500 & 4.2 & [112] \\
\hline & IN625 & LRM & $1000-1500$ & $5.0-13$ & [113] \\
\hline & Rene 142 & $\mathrm{LC}$ & 550 & Not reported & [114] \\
\hline & Nimonic 263 & SLM & 200 & 100 & [115] \\
\hline & IN718 & SLM & 170 & 417 & [116] \\
\hline & Experimental & SLM & 1000 & 2 & [117] \\
\hline & IN718 & SLM & 3000 & Not reported & [118] \\
\hline & IN939 & SLM & 400 & $540-620$ & [119] \\
\hline & IN718 & SMD & $(220 \mathrm{~A})$ & 5 & [120] \\
\hline & Rene 41 & LMD & $4500-5000$ & $5.00-5.83$ & [121] \\
\hline & Rene 80 & SLE & 1000 & $\sim 100$ & [122] \\
\hline & Hastelloy X & SLM & 165-195 & Not reported & [123] \\
\hline & Hastelloy X & SLM & Not reported & Not reported & [123] \\
\hline & IN718 & SLM & Not reported & Not reported & [124] \\
\hline & Ni60A & LMDS & Not reported & Not reported & [125] \\
\hline
\end{tabular}

* EBM = Electron beam melting, DMD = Direct metal deposition, SLM = Selective laser melting, 3D-GMAW $=$ Gas metal arc welding $3 \mathrm{D}$ printing, $\mathrm{DMLS}=$ Direct metal laser sintering, $\mathrm{EBF}^{3}=$ Electron beam freeform fabrication, DMLS = Direct metal laser sintering, SLS = Selective laser sintering, LRM = Laser Rapid Manufacturing, LC $=$ Laser Cladding, SMD = Shaped Metal Deposition, $\mathrm{LMD}=$ Laser Metal Deposition. ${ }^{\dagger}$ Values in parenthesis signify processes where it is more common to report the voltage and current.

Table 2. Process and resulting as-deposited microstructures for iron, aluminum and nickel alloys.

\begin{tabular}{|c|c|c|c|c|c|}
\hline & Alloy & Process & Phases & HV & Ref. \\
\hline \multirow{5}{*}{ Iron alloys } & 4340 & DMD & Ferrite, Martensite, Cementite & $580.5 \pm 100.5$ & [92] \\
\hline & $\mathrm{H} 13$ & DMD & Not reported & $550 \pm 30$ & [94] \\
\hline & H13 & DMD & Fine martensite, retained austenite, fine carbides & $615 \pm 35$ & [95] \\
\hline & ER70S-6 & 3D-GMAW & Polygonal ferrite, acicular ferrite & $184 \pm 15$ & [96] \\
\hline & 420 SS & DMLS & Martensite, little retained austenite & $\ddagger 478 \pm 20$ & [99] \\
\hline \multirow{5}{*}{$\begin{array}{l}\text { Aluminum } \\
\text { alloys }\end{array}$} & Al 2139 & $\mathrm{EBF}^{3}$ & Not reported & $81-103$ & {$[100$} \\
\hline & AlSil0Mg & SLM & FCC dendrites, interdendritic eutectic & $131-141$ & {$[101$} \\
\hline & $\mathrm{Al}-12 \mathrm{Si}$ & Pulsed SLM & FCC dendrites, small eutectic phases & $130-140$ & {$[102$} \\
\hline & $\mathrm{Al}-12 \mathrm{Si}$ & SLM & FCC Al matrix, nanosized Si precipitates & $107-115$ & {$[103$} \\
\hline & AlSi10Mg & SLM & FCC & 114 & {$[104$} \\
\hline
\end{tabular}


Table 2. Cont.

\begin{tabular}{|c|c|c|c|c|c|}
\hline & Alloy & Process & Phases & HV & Ref. \\
\hline \multirow{11}{*}{$\begin{array}{l}\text { Nickel } \\
\text { alloys }\end{array}$} & IN718 & SLM & FCC $-\gamma$, ellipsoidal $\mathrm{Ni} 3 \mathrm{Nb}$ precipitates & $387-398$ & [109] \\
\hline & IN718 & DMD & FCC $-\gamma$ & 255 & [110] \\
\hline & IN718 & SLM & FCC $-\gamma$, fine $\gamma^{\prime}$ precipitates & $331.9-395.8$ & {$[67]$} \\
\hline & Colmonoy 6 & LRM & FCC $-\gamma$, interdendritic eutectic & $700-800$ & [112] \\
\hline & IN625 & LRM & FCC $-\gamma$ & $\ddagger 474.9-574.1$ & {$[113]$} \\
\hline & Rene 142 & LC & Not reported & $410-460$ & {$[114]$} \\
\hline & Experimental & SLM & Not reported & $650-800$ & {$[117]$} \\
\hline & IN718 & SLM & FCC $-\gamma$ & $400-450$ & [118] \\
\hline & IN939 & SLM & FCC $-\gamma$ & 450 & [119] \\
\hline & IN718 & SMD & FCC $-\gamma$, interdendritic carbides/Laves & $245-287$ & [120] \\
\hline & Rene 41 & LMD & FCC $-\gamma$, MC carbides & $418.1-435.1$ & [121] \\
\hline
\end{tabular}

‡: Converted from HRC to HV using Equation (4).

\subsection{Iron Based Alloys}

Due to the high costs of AM compared to conventional casting and forging processes, the use of plain carbon and low alloy steels have not found significant usage for AM applications outside of a few studies [126,127]. Many of the steels used in AM have been tools steels [128-134], studied for specialized repair applications in which high strength and wear resistance is crucial. Tools steels such as M2 and H13 obtain high strengths and hardness due to their propensity to form martensite even at relatively low cooling rates. Additionally, these alloys contain high amounts of carbon which promote the formation of carbides and increase strength and hardness. Typical microstructures of tool steels processed by AM include a martensitic matrix with some carbide precipitation and retained austenite [129,134]. After deposition of tool steels, heat treatment is desirable to increase ductility and toughness. A tempered martensitic microstructure with carbide precipitates results from extended times at high temperatures [131].

Austenitic stainless steels, such as SS304L and SS316L exhibit predominantly austenitic microstructure consisting of cells and columnar dendrites, depending on the type of AM technique and the process parameters. Figure 8 shows an SEM micrograph of the typical columnar dendritic morphology of the austenitic grains encountered for SS316L fabricated using DED-L. Although austenitic stainless steels are dominated by an austenitic matrix, small amounts of delta ferrite can form as a result of thermal cycles and micro-segregation. High cooling rates during solidification favor austenite whereas lower cooling rates tend to yield increasing amounts of delta ferrite [135]. In PBF processes, a fine cellular solidification structure on the order of $1 \mu \mathrm{m}$ is often observed. As austenitic stainless steels often do not precipitate secondary phases or undergo other solid-state transformations, the strength and hardness depend on the fineness of the solidification structure and chemical composition. 


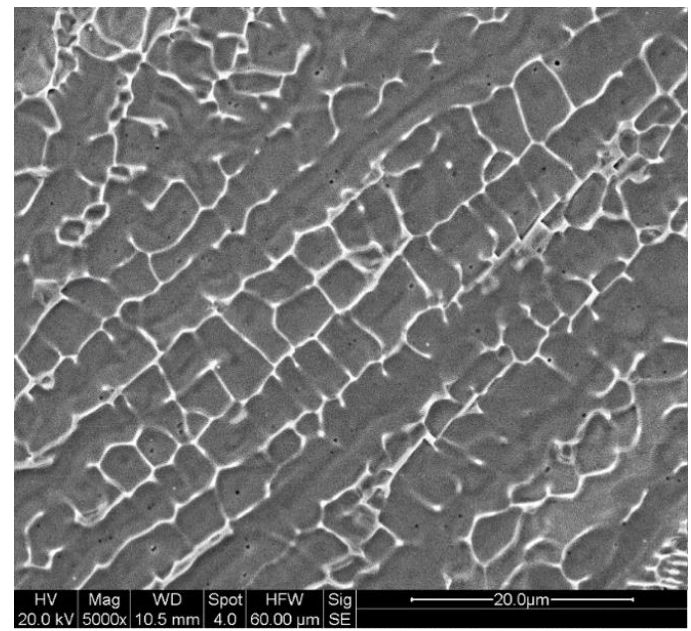

Figure 8. Columnar dendritic microstructure of SS316L deposited by DED-L [53]. Reprinted from [53] with permission from Elsevier.

Figure 9 shows a collection of measured HV as a function of secondary dendrite arm spacing (SDAS) for the austenitic stainless steels SS316 and SS316L processed by DED-L. Both alloys typically exhibit large austenitic columnar grains with a dendritic substructure. Although these alloys are chemically similar, SS316L ( $\leq 0.03 \mathrm{wt} \% \mathrm{C})$ contains slightly less carbon than SS316 $(\leq 0.08 \mathrm{wt} \% \mathrm{C})$ to help improve weldability and prevent sensitization. This small change in composition has pronounced effects on micro-hardness for roughly the same size SDAS with measurements for SS316, although limited, having a hardness of nearly $100 \mathrm{HV}$ higher than those of SS316L. The same effect was observed in Figure 1. Therefore, it is important to perform detailed chemical composition analyses when studying the effects of microstructure on properties as small fluctuations in concentration of carbon can significantly affect hardness.

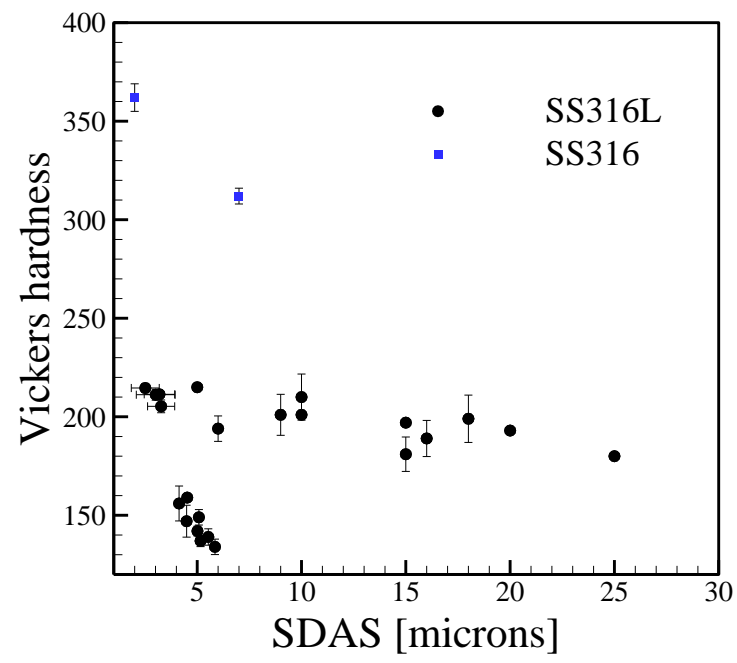

Figure 9. Vickers micro-hardness as a function of secondary arms spacing for stainless steels fabricated by AM from $[45,53,70,136,137]$. Error bars represent the standard deviation in measurements.

Precipitation hardened $(\mathrm{PH})$ stainless steels have received considered attention in the AM community with the most commonly processed alloys being $17-4 \mathrm{PH}$ and $15-5 \mathrm{PH}$. Nominal compositions for the $\mathrm{PH}$ grade stainless steels typically promote the formation of martensite during rapid cooling. Subsequent solutionizing and aging allows for $\mathrm{Cu}$-rich nanoparticles to precipitate in a tempered martensite matrix which determine the final properties. However, microstructures ranging from austenitic/martensitic to primarily martensitic have been reported 
in the AM literature depending on the atomization condition of the powder feedstock and the type of shielding gas used. Multiple investigations [138,139] have shown that when Ar-atomized 17-4PH stainless steel was processed under an Ar atmosphere, a primarily martensitic structure was obtained. However, when nitrogen, an austenite-stabilizing element, was used as a processing gas to melt nitrogen atomized powders, a mixture of primarily austenite and martensite was observed. In the as-deposited conditions, substantial differences in micro-hardness in the two extreme conditions were measured, as the samples with more austenite exhibited a hardness slightly over $200 \mathrm{HV}$ and the martensitic samples had a hardness slightly less than 400 HV [139].

The microstructure evolution during solutionizing and aging is highly dependent on the as-deposited microstructure. Standard solution heat treatments originally developed for wrought alloys may not be applicable due to the heterogeneous microstructures encountered in AM parts. For example, Cheruvathur et al. [140] found that the Vickers hardness of solutionized 17-4PH grade stainless steel was $312 \pm 17 \mathrm{HV}$ compared to a value of $258 \pm 8$ for the as-deposited condition. Although $17-4 \mathrm{PH}$ is classified as a martensitic stainless steel, a mixture of approximately $50 \%$ martensite and $50 \%$ retained austenite was found in the as-deposited condition with small amounts of $\mathrm{NbC}$. After solutionizing and subsequent air cooling, less retained austenite was found in the microstructure, which was attributed to the increase in hardness.

\subsection{Aluminum Alloys}

The aluminum alloys most commonly used in AM processes contain large amounts of $\mathrm{Si}$ which promote eutectic solidification. The lower melting point of eutectic Al-Si alloys, such as Al-12Si and AlSi10Mg, are easier to process via laser-based AM processes compared to other aluminum alloys due to the low absorptivity of $\mathrm{Al}$ over a wide range of wavelengths. Aluminum alloys generally exhibit a cellular or dendritic microstructure consisting of a face centered cubic Al-matrix with fine Si-rich phases in the as-deposited condition when processed by AM. For example, Figure 10 shows cubic silicon phase in a fine cellular/dendritic structure within the face centered cubic aluminum matrix of AlSi10Mg after selective laser melting [141]. Eutectic formation was found to form at the triple points of the cellular/dendritic structure. Although cells and dendrites predominate in much of the literature, partial equiaxed microstructures [142] can be observed as shown in Figure 11 depending on the solidification parameters.

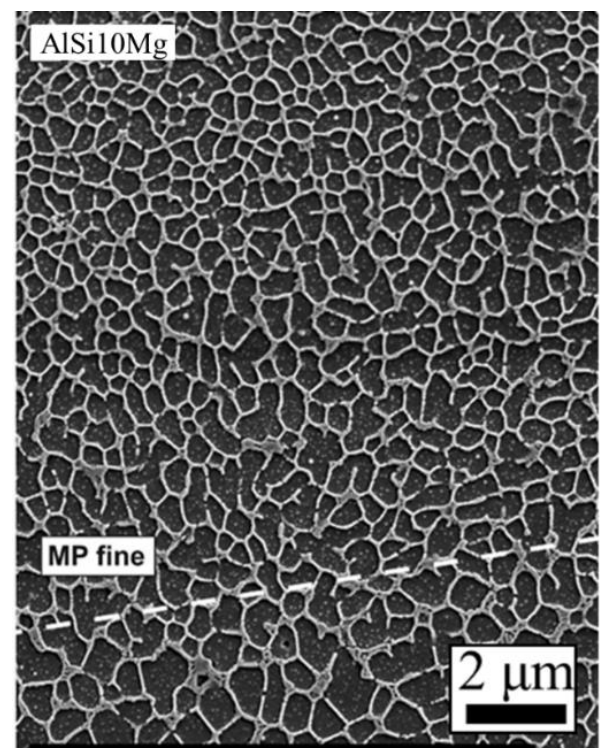

Figure 10. As-deposited microstructure of AlSi10Mg alloy fabricated by selective laser melting showing a fine cellular/dendritic structure with small amounts of eutectic [141]. Reprinted from [141] with permission from Elsevier. 

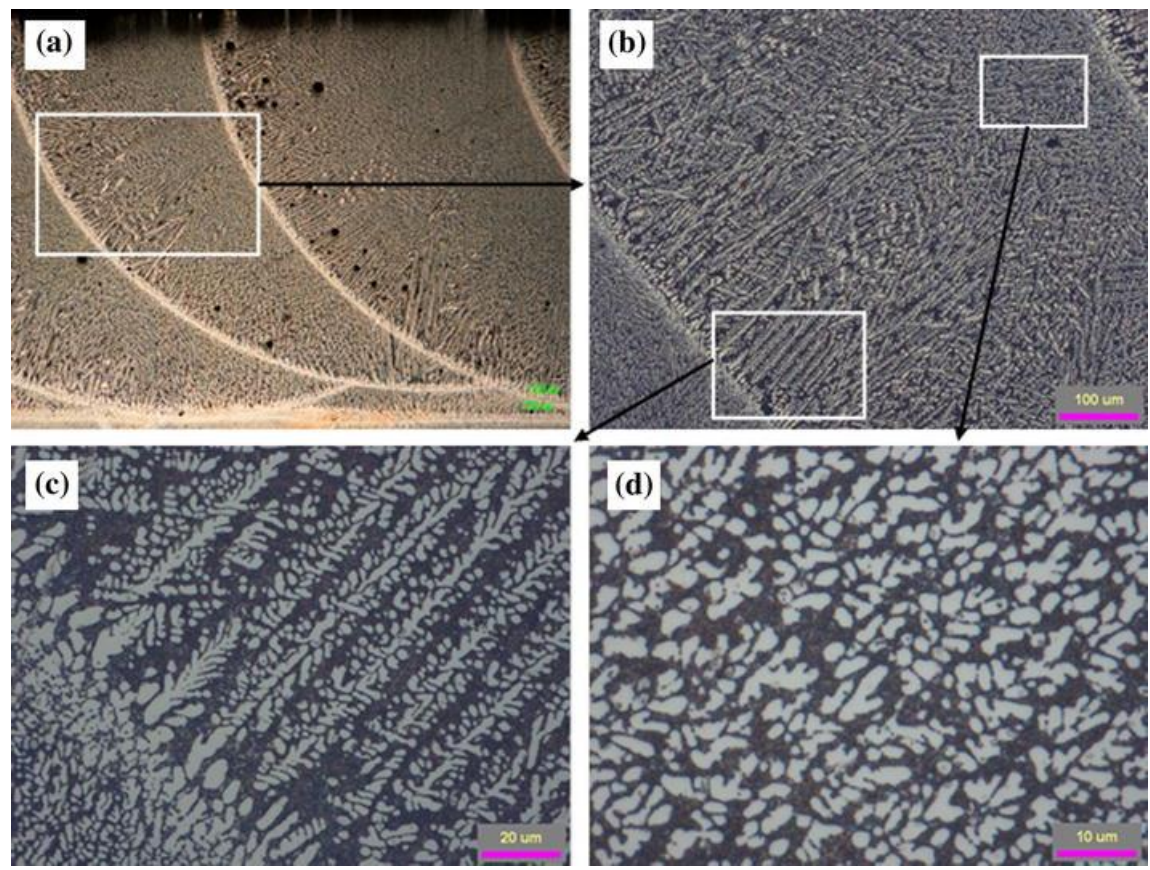

Figure 11. Microstructure of laser deposited Al 4047 showing dendritic and equiaxed structures at different locations within the same layer [142]. Reprinted from [142] with permission from Springer Nature.

As precipitation hardenable aluminum alloys rely on aging heat treatments to achieve enhanced properties, the high strengths and hardness observed in as-fabricated alloys stem from the fine solidification structure. Although there is sparse data fragmented over multiple aluminum alloy systems, Figure 12 shows a collection of HV values plotted as a function of SDAS from AM. Selected data from directionally solidified aluminum alloys Al-3Cu, Al-1Ti and Al-3Si [143] is shown for comparison. A combination of high cooling rates and significant amounts of alloying elements, namely $\mathrm{Si}$, lead to fine secondary dendrite arm spacing and high hardness in the alloys processed by AM. However, any attempts to link microstructure to properties should be limited to single compositions and Figure 12 merely shows a collection of data to demonstrate the fineness of AM microstructures in comparison to other processes. Any significant deviations in chemical composition that affect solidification requires separate analysis.

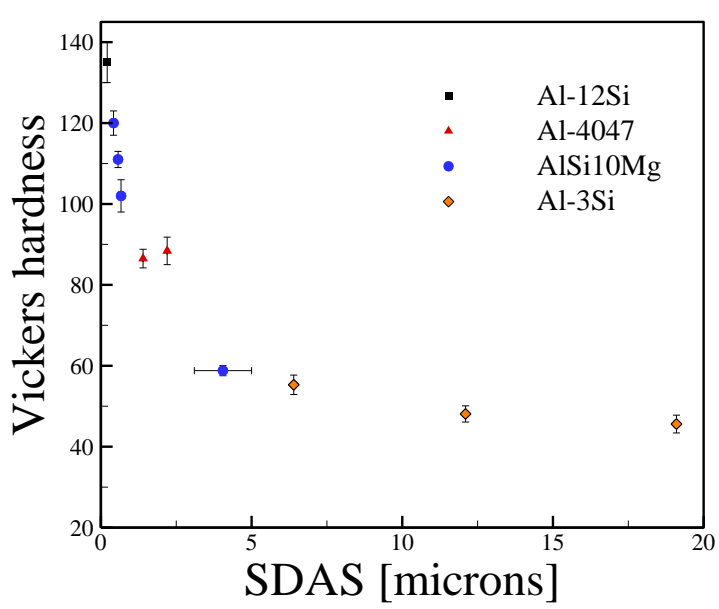

Figure 12. Vickers micro-hardness as a function of secondary arms spacing for aluminum alloys fabricated by AM from [112,142,144,145] and selected data for directional solidification of Al-3Si from Kaya et al. [143] for comparison. Error bars represent the standard deviation in measurements. 
Although high strengths and hardness have been obtained after the AM of aluminum alloys, as-deposited components typically suffer from poor ductility. Investigations into the effects of post-process heat treatments on the mechanical properties of AlSi10Mg processed by PBF-L have resulted in interesting conclusions. Results from Aboulkhair et al. [146] showed that when applying standard T6 heat treatments (solutionizing + artificial aging) at various solutionization times, the Vickers hardness of heat treated samples (between 75-100 HV) was always less than the hardness in the as-deposited condition $(\sim 110 \mathrm{HV})$. Although Li et al. [147] reported similar findings, their results showed that the hardness after solutionizing was, in fact, greater than the hardness after artificial aging. After microstructural examination, it was found that Si particles formed during solutionization and subsequent artificial aging coarsened the particles to an extent similar to overaging in commonly processed aluminum alloys. However, Kempen et al. [148] achieved about a 12\% increase from the as-deposited hardness (136 \pm 9 to $152 \pm 5 \mathrm{HV})$ when directly applying an artificial aging heat without a solutionizing step.

The use of HIP as a post-processing technique has found widespread use across many different alloys systems used in AM. In most cases, a dramatic effect can be observed when comparing the hardness of as-deposited and post-HIP conditions. During the PBF-L of AlSi10Mg [149], subsequent HIP treatment resulted in a hardness value $(60 \pm 5 \mathrm{HV})$ more than half of that of the as-deposited condition (125 $\pm 5 \mathrm{HV})$ due to significant microstructural coarsening and stress relief. Similarly, Tradowsky et al. [150] found that for machined AlSi10Mg samples fabricated by PBF-L, yield strength decreased by more than $60 \%$ after post-process HIP. However, the loss of strength was compensated by a substantial increase in percent elongation from approximately $5 \%$ in the as-deposited condition to about $21 \%$ after HIP.

\subsection{Nickel Alloys}

Nickel alloys are some of the most complex alloys used in AM applications due to the large amounts of alloying elements that can result in various types of secondary phase precipitation which ultimately affect mechanical properties. The as-deposited microstructures of nickel alloys are highly dependent on thermal histories and chemical composition. Figure 13 shows microhardness as a function of SDAS for the DED-L of IN625, IN718 and Waspaloy. In the case of IN625, data points are confined to a rather tight grouping with an average micro-hardness and SDAS of approximately $250 \mathrm{HV}$ and slightly less than $4 \mu \mathrm{m}$, respectively. Although IN625 is generally classified as a solid solution strengthened alloy, secondary phases often form in both welding and AM due to significant micro-segregation. However, these secondary phases (Laves, MC carbide) often form upon solidification and appreciable nucleation and growth in the solid state during AM processing is uncommon.

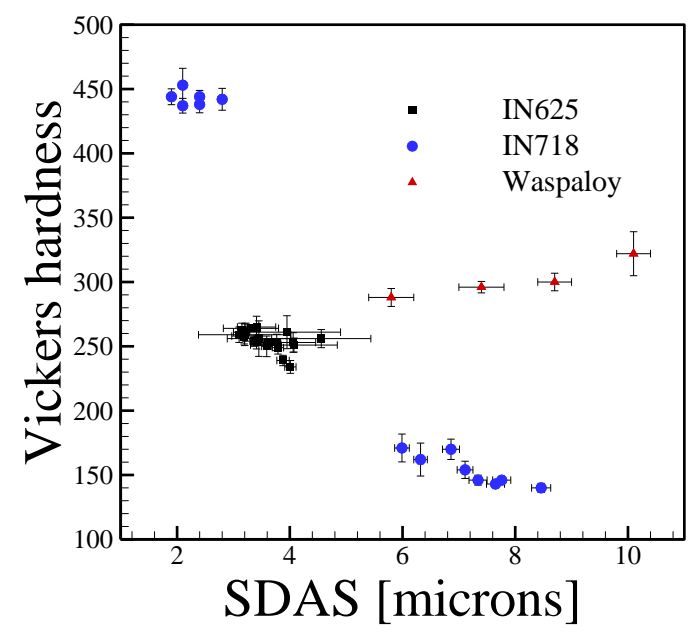

Figure 13. Vickers microhardness as a function of secondary arms spacing for nickel alloys fabricated by AM from [137,151-155]. Error bars represent the standard deviation in measurements. 
In the case of IN718, the highest HV values in Figure 13 correspond to a post-process heat treatment where the lower values were measured in the as-deposited state. It is clear from this comparison that the changes in hardness due to SDAS is negligible when compared to the effects of precipitation hardening. Interestingly in the case of the Waspaloy data, a positive correlation is observed between HV and SDAS. At first, this may seem counterintuitive, however the increases in SDAS were a result of deposits with different layer numbers with a higher number of layers corresponding to higher SDAS. As more heat was accumulated in the build and cooling rates decreased, microstructural coarsening occurred simultaneously with nucleation and growth of $\gamma^{\prime}$ precipitates. Therefore, the observed hardness is contributed by both the coarsening as well as the precipitation of $\gamma^{\prime}$ phase.

The as-deposited microstructures in AM alloys vary drastically from those of wrought counterparts for which standard heat treatments were developed. Consequently, large amounts of elemental segregation often observed in AM parts are expected to contribute to heat treatment responses that vary significantly from those of wrought parts. Zhang et al. [156] showed that after just five minutes at the manufacturer recommended stress relief temperature $\left(870{ }^{\circ} \mathrm{C}\right)$, IN625 processed by PBF-L began to nucleate and grow deleterious $\delta$-phase. Figure 14 shows the time evolution of the needle-shaped precipitates during stress-relieving. For comparison, an isothermal transformation diagram for wrought IN625 [157] does not predict the formation of $\delta$-phase until approximately $10 \mathrm{~h}$ at $870{ }^{\circ} \mathrm{C}$. The presence and morphology of intermetallic phases such as those shown in Figure 14 act as stress concentrators and can be detrimental to the ductility and toughness of materials. Instances such as these may prompt the need for developing standard heat treatments specially designed for AM materials to avoid undesirable microstructural evolution.
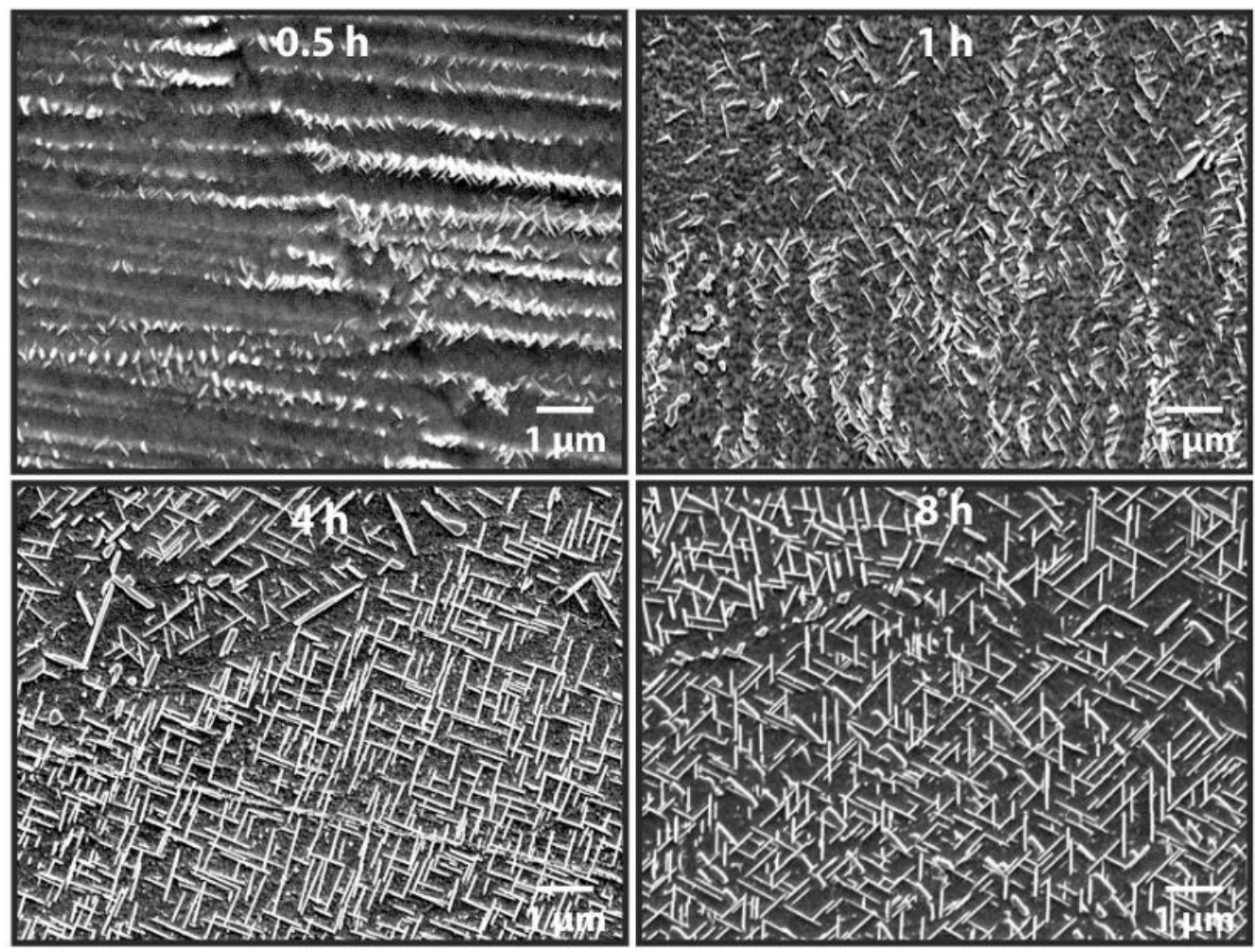

Figure 14. The precipitation and growth of $\delta$ phase at various times in PBF-L IN625 subjected to a standard stress relief heat treatment at $870^{\circ} \mathrm{C}$ [156]. Reprinted from [156] with permission from Elsevier.

Vilaro et al. [115] reported hardness increases during $8 \mathrm{~h}$ stress relief heat treatments of PBF-L Nimonic 263 up to approximately $800{ }^{\circ} \mathrm{C}$. Even though the residual stresses present in the as-deposited condition were greatly reduced at $600^{\circ} \mathrm{C}$, a slight increase in micro-hardness was observed. It was proposed that the high-density dislocation structure was unable to restore due to the presence of very 
small $(<10 \mathrm{~nm}) \gamma^{\prime}$ particles that pinned dislocation motion at these temperatures which, along with the precipitation M23C 6 carbides, increased hardness. It was not until a heat treatment above the $\gamma^{\prime}$ solvus temperature $\left(\sim 960^{\circ} \mathrm{C}\right)$ was used that the precipitates dissolved and the dislocation density was reduced.

Although IN718 is a nickel alloy, other elements like $\mathrm{Al}, \mathrm{Cr}, \mathrm{Fe}, \mathrm{Mo}, \mathrm{Nb}$ and Ti constitute nearly half of the alloy mass which aid in the nucleation and growth of $\gamma^{\prime}$ and $\gamma^{\prime \prime}$ precipitates. Although slight variations in time and temperatures have been used, post-processing of IN718 components fabricated by AM generally follow standard heat treatments including solutionization at $980^{\circ} \mathrm{C}$ for $1 \mathrm{~h}$ followed double aging at $720{ }^{\circ} \mathrm{C}$ for $8 \mathrm{~h}$ and $620^{\circ} \mathrm{C}$ for $8 \mathrm{~h}$. The box-and-whisker plot in Figure 15 shows a collection of literature data for the hardness of IN718 parts at various stages of post-processing after AM fabrication. Individual points in Figure 15 represent outlying data. Clearly, significant advantages are gained in post-process heat treating to achieve properties that are otherwise unattainable in as-deposited parts.

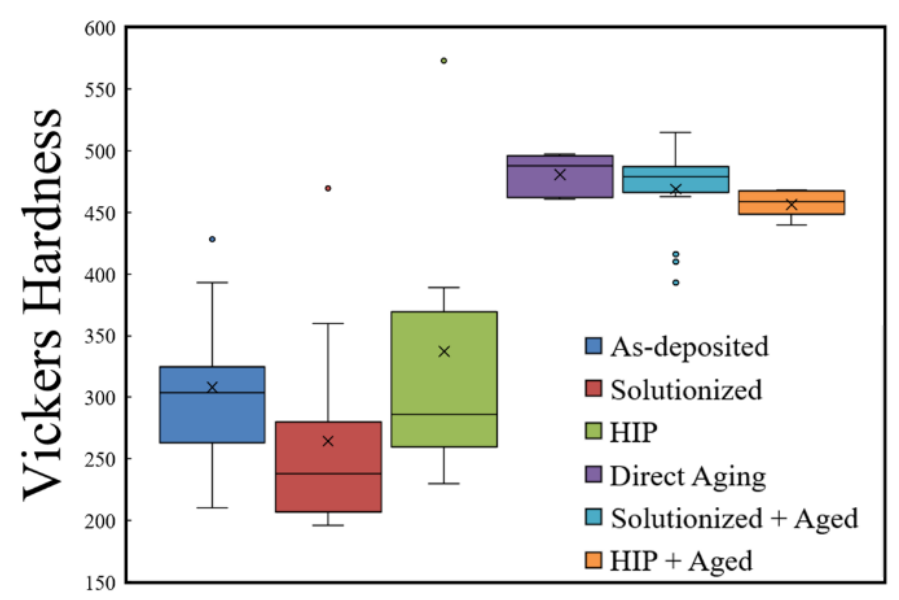

Figure 15. Box and whisker plot showing the variation in Vickers hardness of IN718 parts fabricated by DED-L [118,158-161], PBF-L [67,162-168] and PBF-EB [169,170] AM and subjected to various post process heat treatments.

An effort was undertaken by Sames et al. [171] to circumvent post-processing of IN718 while still achieving peak-aging properties. An in-situ heating method was used on a PBF-EB system where the build was consistently held at high temperatures to promote aging. A comparison of the Vickers hardness measured after the in-situ heat treatment and under fast and slow cooling is shown in Figure 16. Although the measurements showed that optimal hardness values were attainable, further tensile testing revealed significantly lower strength and elongation than control specimens due to the presence elongated cracks. In another study, Schwab et al. [172] used a similar in-situ heating method to enhance the properties of Ti-5553 during PBF-L through substrate heating. About a $60 \%$ increase in Vickers hardness was achieved and higher compressive strength was measured when comparing the heat-treated deposit to the samples with no substrate heating.

Khayat and Palmer [155] found for multiple IN625 feedstocks with varying iron contents fabricated by DED-L that HIP resulted in a Vickers hardness roughly $40 \mathrm{HV}$ lower than the as-deposited material. Although the volume fraction of secondary phases increased during post-processing, which normally contribute to increased hardening, it is likely that the observation was outweighed by other factors like decreased dislocation density and elimination of the fine dendritic structure. 


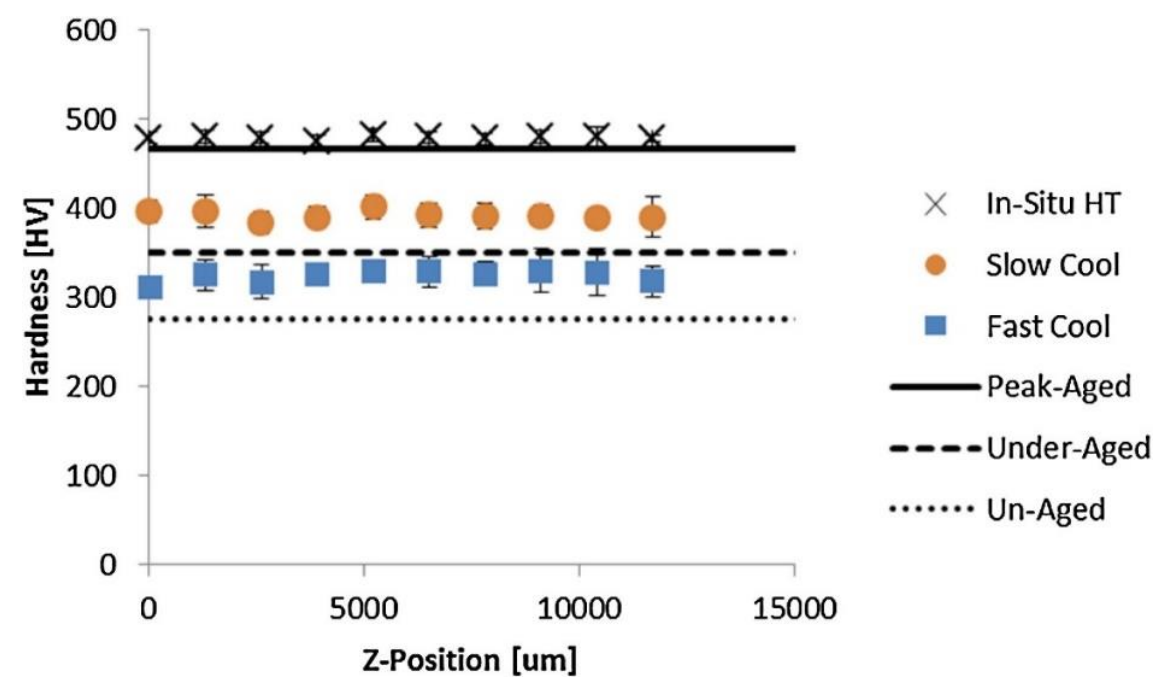

Figure 16. Measured Vickers hardness during PBF-EB of IN718 subjected to different cooling cycles and in-situ heat treatment [171]. Reprinted from [171] with permission from Elsevier.

\subsection{Titanium Alloys}

The combination of high strength and low density make titanium alloys an attractive alloy for AM in aerospace applications. The Ti-6Al-4V alloy is the most studied of the titanium alloys. The microstructure of Ti-6Al-4V consists of hexagonal close packed $(\alpha)$ and body centered cubic $(\beta)$ phases as shown by the phase diagram in Figure 17. The addition of Al stabilizes $\alpha$ phase while V stabilizes $\beta$. Generally, as-deposited microstructures after powder bed fusion (PBF) AM exhibit a fine martensitic $\left(\alpha^{\prime}\right)$ structure with acicular laths while the microstructures in directed energy deposition (DED) AM typically have a coarser structure consisting of lamellar $\alpha$ and small amounts of $\beta$ [1]. Figure 18a,b shows representative micrographs of Ti-6Al-4V fabricated by DED and PBF AM.

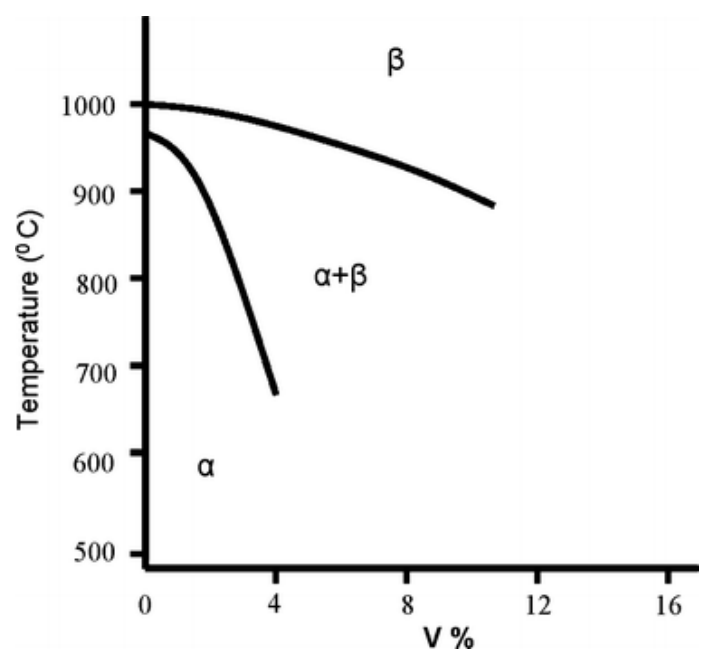

Figure 17. A portion of the Ti-Al-V phase diagram [173] for a constant aluminum concentration of $6 \mathrm{wt} \%$. Reprinted from [173] with permission from Springer Nature. 

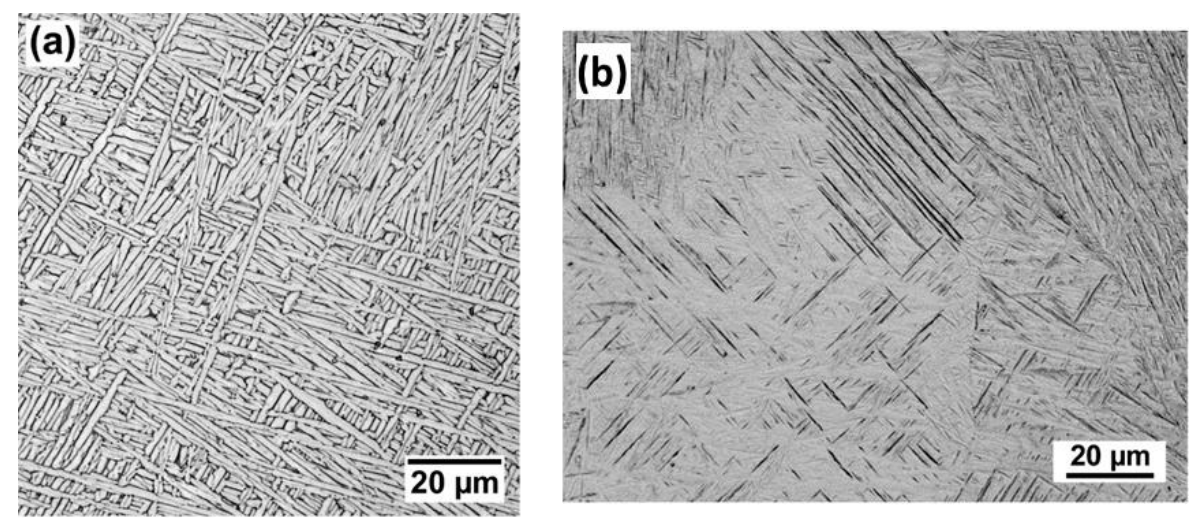

Figure 18. Representative micrographs of Ti-6Al-4V fabricated by (a) DED and (b) PBF after stress relieving [1]. Components fabricated by DED typically display coarse lamellar $\alpha$-laths with small amounts of $\beta$ while PBF components have much finer acicular martensite $\left(\alpha^{\prime}\right)$. Reprinted from [1] with permission from Elsevier.

Ti-6Al-4V undergoes a transformation from the body centered cubic $\beta$-phase to a two phase structure consisting primarily hexagonally close-packed $\alpha$-phase and small amounts of $\beta$-phase at a temperature of approximately $1000{ }^{\circ} \mathrm{C}$ [16]. The solid-state transformation can lead to quantifiable microstructural features within grains and depending on the cooling rate through transition temperature, the $\alpha$-phase can exhibit different morphologies. In many AM builds, needle-like $\alpha$-laths are present inside the large, prior $\beta$ grains. Multiple studies have investigated the quantitative relationship between $\alpha$-lath width and mechanical properties like hardness, strength and ductility. A collection of measured data correlating $\alpha$-lath width to Vickers hardness is presented in Figure 19, which shows a decrease in hardness with the coarsening of the lath for DED-L and PBF-EB.

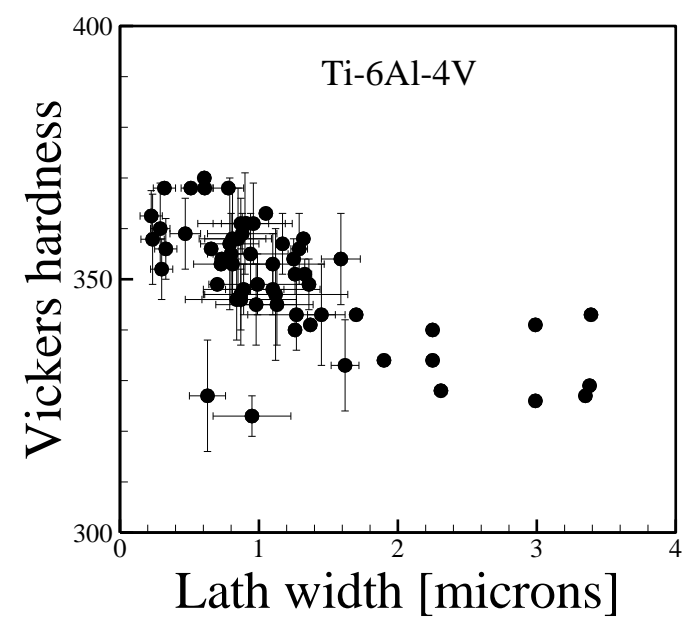

Figure 19. Vickers micro-hardness as a function of alpha lath width for Ti-6Al-4V fabricated by AM from [54,152,174-179]. Error bars, where available, represent the standard deviation in measurements.

Heat treatments are used to relieve residual stresses and coarsen $\alpha$-phase morphology for increasing ductility and toughness at the expense of strength and hardness in Ti-6Al-4V components fabricated by AM. A similar behavior was observed during the wire fed DED-L of Ti-6Al-4V that was stress relieved at $600{ }^{\circ} \mathrm{C}$ for $4 \mathrm{~h}$. The Vickers hardness of multiple samples deposited with different process parameters $(\sim 327 \mathrm{HV})$ was found to increase to approximately $343 \mathrm{HV}$ after stress relieving. It was suggested that a combination of precipitation hardening and solid solution strengthening contributed the increase, as the selected heat treatment temperature can also be used for aging and energy dispersive spectroscopy showed slightly less segregation compared to the as-deposited condition. 


\subsection{Grain Size}

Grain size refining is known to have a significant impact on the strength and hardness of metals and alloys. The early works of Hall [180] and Petch [181,182] described the effect of grain size, $d$, on yield strength, $\sigma_{y}$, in the well-known Hall-Petch relation,

$$
\sigma_{y}=\sigma_{0}+\frac{k_{y}}{\sqrt{d}}
$$

where $\sigma_{0}$ and $k_{y}$ are material constants that represent the yield stress of a grain-free material and the strengthening coefficient, respectively. The expression was formulated to explain the observed phenomenon that fine-grained materials exhibit higher stresses prior to yielding compared to alloys with coarse grains. At grain boundaries where there is a change in crystallographic orientation, dislocations require more energy to move from one grain to another, thereby impeding dislocation motion. Therefore, higher grain boundary area per unit volume (smaller grain size) effectively strengthens a material by blocking dislocation motion.

The works of Tabor [183] and Cahoon [184] have shown that hardness is directly proportional to yield strength. Recently, Keist and Palmer [1] investigated the strength-hardness relationships for the DED of Ti-6Al-4V using both laser and electron beam heat sources. Their correlation is plotted along with independent experimental data for Ti-6Al-4V components fabricated by PBF and DED processes in Figure 20. Similarly, a collection of data for the AM of SS316L is shown in Figure 21. While scatter in data from multiple researchers can be expected, both Figures 20 and 21 clearly show positive correlations between yield strength and hardness for AM alloys fabricated by multiple techniques. Therefore, Equation (2) can also be applied to studies involving the relationship between hardness and grain size. When considering the micro-hardness measurement using a Vickers indenter, the relationship takes a similar form, where yield strength is replaced by Vickers hardness, $H V$ and $H V_{0}$ is material constant reference hardness value replacing $\sigma_{0}$. As hardness is a measurement of localized plastic deformation, a hardness indent may be fully encompassed within a grain depending on the load, dwell time and size of grains and the effect of strengthening due to dislocation propagation and pileup at grain boundaries may not be captured. Also, significant variability in measurements could result depending on where measurements are taken with respect to grains (center of grain, boundary, triple junction, etc.). Regardless, the acquisition of ample hardness measurements for many AM microstructures provides a simple means for investigating the effect of grain size on hardness.

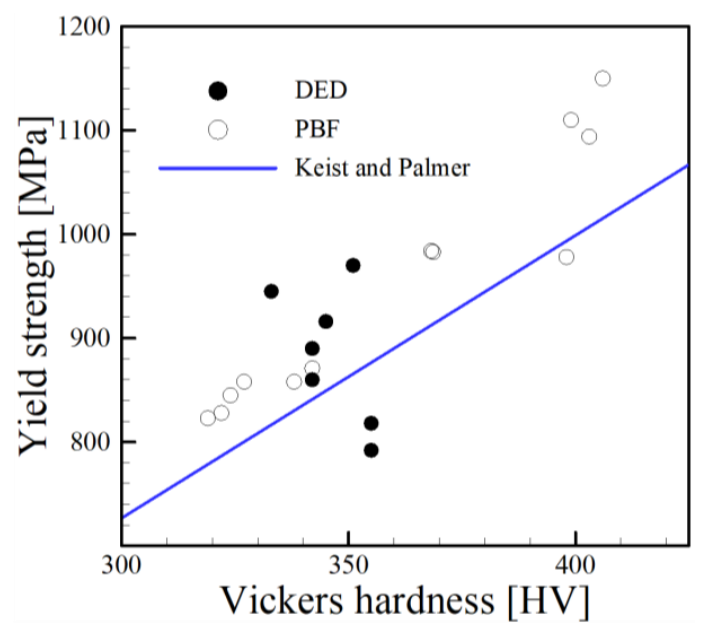

Figure 20. Comparison between the correlation developed by Keist and Palmer [1] and independent experimental data $[54,55,57-59,185-187]$ for yield strength and hardness measurements spanning multiple AM processes. 


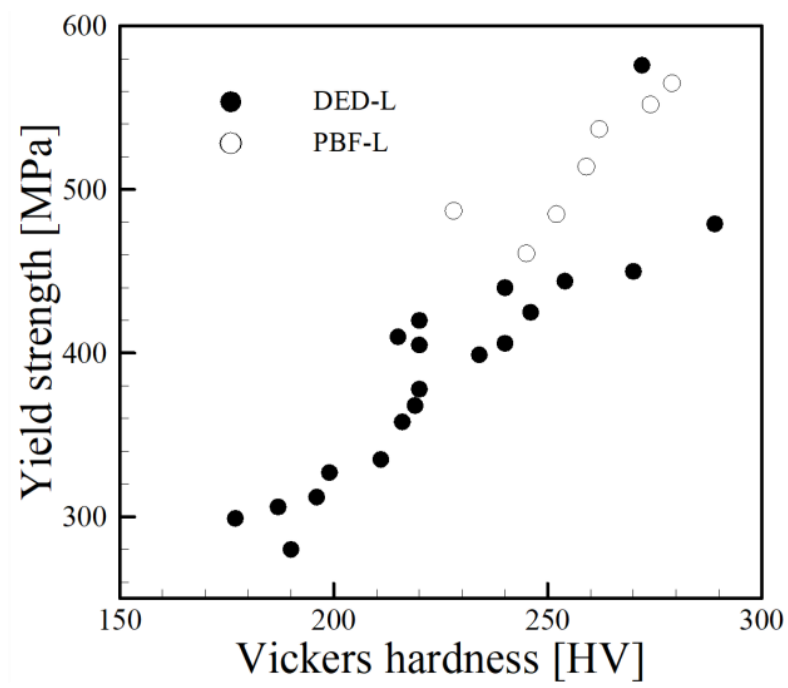

Figure 21. A collection of independent experimental data showing a comparison between measured yield strength and Vickers hardness for SS316L fabricated by AM $[46,48,49,188,189]$.

The Hall-Petch relation was originally developed for equiaxed grains and has found good agreement with experimental results in the grain size range on the order of approximately a few to hundreds of microns. Grain sizes in AM alloys typically fall within this range, however many grains have a columnar rather than equiaxed morphology. Also, grain sizes in PBF processes exhibit smaller grain sizes compared to DED processes. In the AM of IN625 for example, Li et al. [190] measured grain sizes $<40 \mu \mathrm{m}$ after PBF-L while Khayat and Palmer [155] measured sizes in the hundreds of microns for DED-L. Typically, aspect ratios in AM, which are defined as the ratio of grain length to grain width, range between 1 (equiaxed) and 10 (elongated columnar). As-deposited microstructures usually exhibit lower aspect ratios than heat treated samples where significant growth along the length dimension can occur. As relationships between grain size and yield strength are commonly reported in AM literature, it is important for researchers to be specific about the grain dimension used for analysis.

Since grain coarsening is a thermally activated process, the amount of time that an alloy remains at high temperatures ultimately determines the size of grains. Therefore, high cooling rates such as those encountered in PBF processes tend to yield small grain sizes while low cooling rates in high power DED processes exhibit larger grains. Experimental data $[88,188]$ relating cooling rate to grain size and Vickers hardness for the AM of SS316L is shown in Figure 22. The data includes measurements from both DED-L and PBF-L processes at various combinations of laser power and scanning speed. In each study, the average grain diameter decreased with an increase in cooling rate. Consequently, an inverse relationship was obtained between Vickers hardness and average grain diameter, resulting in the Hall-Petch effect.

Wang et al. [4] studied the effects of processing conditions and microstructural features on the tensile properties of SS304L during DED-L. In their discussion, the grain dimension was defined as the average measured length of the grain in the direction of loading. It was found that the measured yield strength and grain sizes obeyed the Hall-Petch relation. Interestingly, the yield and tensile strengths measured in the transverse (parallel to the long grain axis) and longitudinal (parallel to the short grain axis) showed no clear anisotropic trends. In fact, a collection of literature data in a recent review [17] showed that although the microstructures of AM alloy components exhibit elongated columnar grains, the amount of anisotropy is negligible when comparing tensile properties in orthogonal directions. This finding is summarized in Figure 23 for different alloys and AM processes. Data points near the dotted lines in Figure 23 represent little anisotropy while those that stray from the line exhibit more anisotropic behavior. 


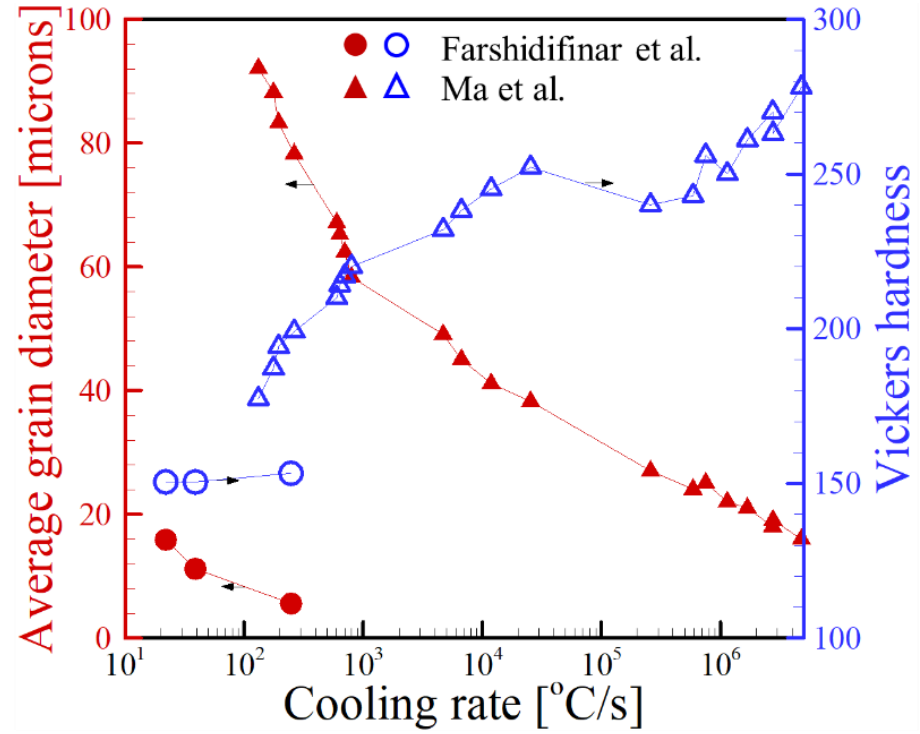

Figure 22. The relationship between cooling rate, average grain diameter and Vickers hardness for the AM of SS316L $[88,188]$. The cooling rate on the horizontal axis is plotted with a logarithmic scale and black arrows indicate the $y$-axis for each data set.
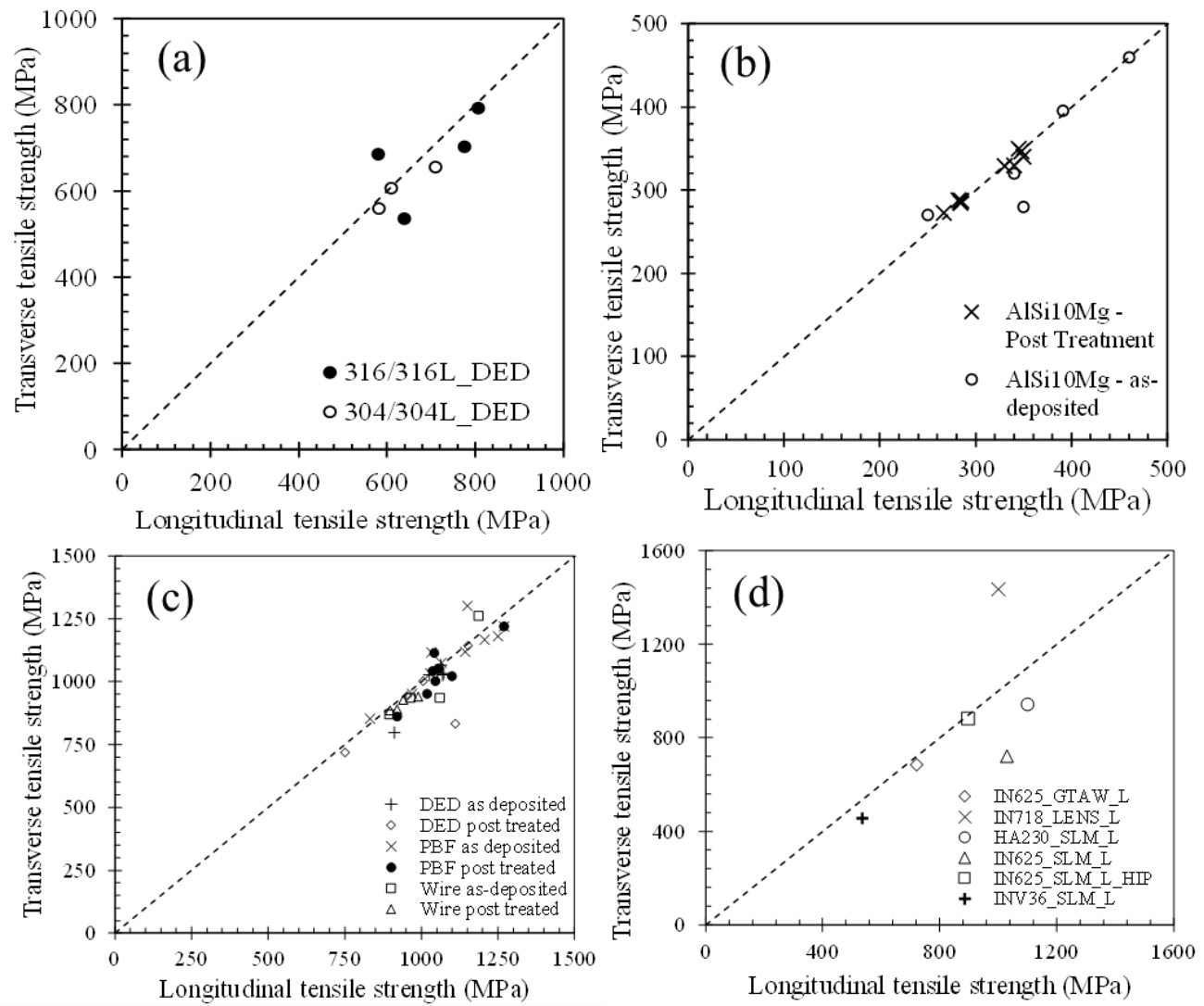

Figure 23. An analysis of anisotropic behavior [17] through a comparison between the transverse and longitudinal tensile strengths in additively manufactured (a) stainless steels $[4,45,46,48,191]$, (b) aluminum alloy AlSi10Mg [105,106,192-196], (c) Ti-6Al-4V [54,57,89,197-209] and (d) nickel alloys [210-215]. Data points deviating from the dashed one-to-one line are exhibit more anisotropy compared to those lying close to the line. Reprinted from [17] with permission from Elsevier. 


\subsection{Dislocations in AM Materials}

Although no investigations have directly examined the impact of dislocation structures on hardness in AM materials, it is important to discuss the role of dislocations on strengthening in general. The scale of dislocations requires experimental observation to be performed by transmission electron microscopy and Figure 24 shows an example of dislocations in a single crystal alloy fabricated by PBF-EB. In conventional metals processing, parts are often work hardened to achieve desired properties, which effectively uses plastic deformation to introduce a high density of dislocations. Dislocations can exist in many different forms such as edge, screw or mixed, where each introduces strain in the crystal lattice which affects the movement of neighboring dislocations during plastic deformation. In most introductory materials science and engineering textbooks, the tradeoff between strength and ductility is formulated in which any increase in strength due to work hardening is accompanied by a loss in ductility. In a recent work by Wang and co-workers [216], a hierarchy of microstructures spanning multiple orders of magnitude was attributed to help overcome the conventional strength-ductility tradeoff for PBF-L of SS316L. Very fine cellular walls with high dislocation densities and elemental segregation were found to pin dislocation motion and promote twinning, which ultimately lead to an increase in both strength and ductility due to a steady work hardening behavior.

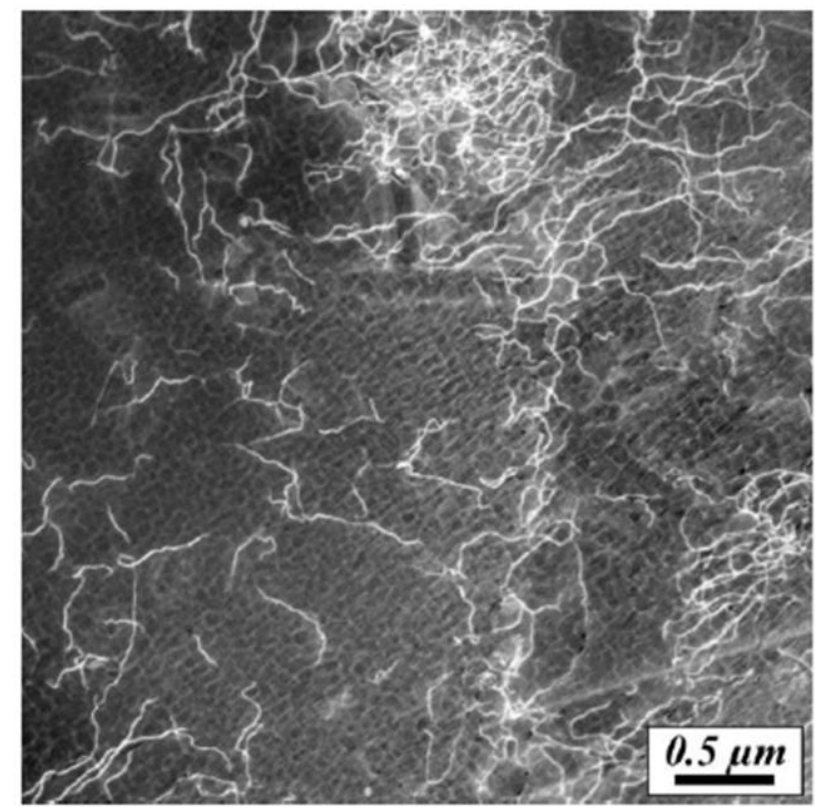

Figure 24. TEM micrograph of dislocations in nickel-based superalloy CMSX-4 processed by PBF-EB AM [217].

In a recent review, Gorsse et al. [19] offered a calculation procedure to determine the upper limit of dislocation density $\left(5 \times 10^{15} \mathrm{~m}^{-2}\right)$ for steels by assuming that all linear thermal strain is accompanied by dislocations upon cooling after solidification. This rough estimation is in good agreement with reported dislocation densities of AM materials in Table 3. Overall, the dislocation densities are comparable to those determined in wrought materials, which is uncharacteristic for materials that have not been work hardened. Moreover, the dislocations in AM materials are often organized into networks [218], as shown in Figure 25a. As in conventional materials, heat treatment will effectively lead to a reduction in dislocation density as shown in Figure 25b. Future research can take advantage of the unique dislocation structures in AM materials if the macroscopic process can be used to control the sub-micron microstructural features [216] 
Table 3. A summary of dislocation densities reported for AM alloys.

\begin{tabular}{cccc}
\hline Alloy & Process & Dislocation Density $\left.\mathbf{( m}^{-\mathbf{2}}\right)$ & Reference \\
\hline SS316L & PBF-L & $1.5 \times 10^{14}$ & {$[219]$} \\
SS316L & PBF-L + Solutionized & $9.7 \times 1013$ & {$[219]$} \\
SS316L & Hot worked + Solutionized & $3.5 \times 10^{13}$ & {$[219]$} \\
SS316L & DED-L & $2.77 \times 10^{14}$ & {$[220]$} \\
SS304L & DED-L & 4.31 to $7.45 \times 10^{12}$ & {$[220]$} \\
SS304L & PBF-EB & $2.72 \times 10^{14}$ & {$[220]$} \\
SS304L & Wrought & $1.84 \times 10^{14}$ & {$[221]$} \\
CrMnFeCoNi & DED-L & 0.89 to $1.19 \times 10^{14}$ & {$[222]$} \\
IN718 & PBF-L & $2.00 \times 10^{13}$ to 5.62 $\times 10^{15}$ & {$[223]$} \\
Nb & PBF-EB & $10^{13}$ to $10^{14}$ & {$[224]$} \\
Ti-6Al-4V & DED-EB + HIP & $10^{11}$ & {$[224]$} \\
Ti-6Al-4V & DED-EB + Stress relieved & $10^{15}$ & {$[225]$} \\
SS304L & PBF-L & $(3.8 \pm 1) \times 10^{14}$ & {$[225]$} \\
SS304L & DED-L & $(2.5 \pm 1) \times 10^{14}$ & {$[225]$} \\
SS304L & Wrought (deformed) & $(6.8 \pm 1) \times 10^{14}$ & \\
\hline
\end{tabular}
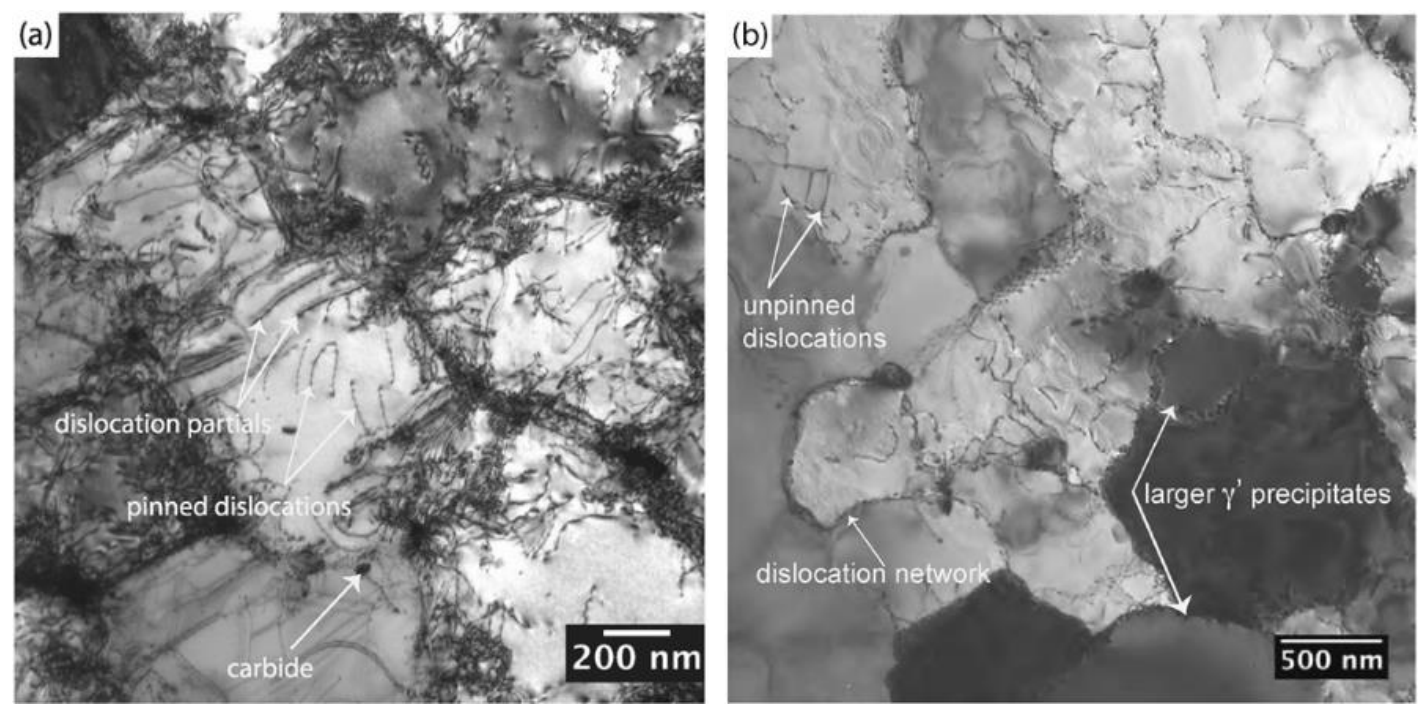

Figure 25. Dislocation structures in nickel-based superalloy CM247LC fabricated by PBF-L [218] showing (a) high dislocation density in the as-deposited condition, especially near cell edges and (b) reduced dislocation density after heat treatment at $1230^{\circ} \mathrm{C}$ for $2 \mathrm{~h}$ followed by air cooling. Reprinted from [218] with permission from Elsevier.

\section{Compositional Variables}

\subsection{Iron Alloys}

A particularly useful approach for predicting properties of steels that has been previously used in the welding community is through the carbon equivalent [226]. The carbon equivalent can take on many forms that include various alloying elements to best suit the target application. The HV for various iron-based alloys can be related to composition using the critical weldability $\left(\mathrm{P}_{\mathrm{cm}}\right)$, which was originally derived for evaluating crack susceptibility for a wide variety of alloy steels, given as [227]:

$$
\mathrm{P}_{\mathrm{cm}}=\mathrm{C}+\frac{\mathrm{Si}}{30}+\frac{\mathrm{Mn}+\mathrm{Cu}+\mathrm{Cr}}{20}+\frac{\mathrm{Ni}}{60}+\frac{\mathrm{Mo}}{15}+\frac{\mathrm{V}}{10}+5 \mathrm{~B}
$$

All elements in Equation (3) are expressed in weight percent. The average HV values from independent experimental data $[91-99,226]$ were plotted versus the $\mathrm{P}_{\mathrm{cm}}$ of the alloy for the following ranges of alloying elements: $0.02-0.99 \mathrm{wt} \% \mathrm{C}, 0-10.2 \mathrm{wt} \% \mathrm{Co}, 0-13.3 \mathrm{wt} \% \mathrm{Cr}, 0.2-1.62 \mathrm{wt} \% \mathrm{Mn}$, 
0.06-7.97 wt \% Mo, 0.15-18.8 wt \% Ni, 0.011-0.025 wt \% P, 0.29-1.02 wt \% Si, 0-0.88 wt \% Ti, 0.03-2.01 wt \% V and 0-6.32 wt \% W. Since different measurement methods such as the Rockwell C hardness test are used for steels, a conversion between the hardness scales is needed. The following relationship was used to convert from the Rockwell C (HRC) to the HV scale [228]:

$$
\mathrm{HV}=111 \mathrm{e}^{0.0316(\mathrm{HRC})}
$$

Figure 26 shows that a linear fit is achieved between HV and composition for data from AM shown in Table 4. It is well-accepted that process variables affect hardness of steels in AM based on many factors that include microstructural features. However, the linearity of Figure 26 shows that chemical composition of steels can provide an approximate value of hardness independent of the AM process variables selected.

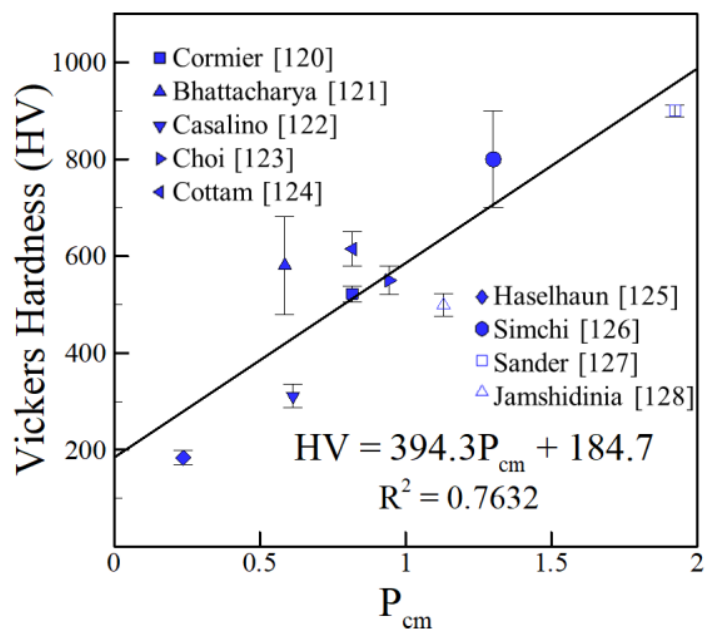

Figure 26. Experimentally measured hardness [91-99] vs. $\mathrm{P}_{\mathrm{cm}}$ of iron-based alloys for AM. 
Table 4. Compositions (in wt \%), $\mathrm{P}_{\mathrm{cm}}$ values and average HV numbers for iron-based alloys.

\begin{tabular}{|c|c|c|c|c|c|c|c|c|c|c|c|c|c|c|c|}
\hline Alloy & $\mathrm{C}$ & Co & $\mathrm{Cr}$ & $\mathrm{Cu}$ & Mn & Mo & $\mathrm{Ni}$ & $\mathbf{P}$ & $\mathbf{S i}$ & $\mathrm{Ti}$ & $\mathbf{V}$ & $\mathbf{W}$ & $\mathbf{P}_{\mathrm{cm}}$ & Average HV & Ref. \\
\hline $\mathrm{H} 13$ & 0.37 & - & 4.99 & - & 0.2 & 1.1 & - & 0.011 & 1.02 & - & 0.8 & - & 0.817 & $\ddagger 498.5 \pm 14.5$ & [91] \\
\hline 4340 & 0.42 & - & 0.9 & - & 0.74 & 0.45 & 2.63 & - & 0.29 & - & - & - & 0.586 & $580.5 \pm 100.5$ & [92] \\
\hline 18Ni300 Maraging steel & 0.02 & 10.2 & - & - & - & 4.2 & 18.8 & - & - & 0.88 & - & - & 0.613 & $\ddagger 323.5 \pm 21.5$ & [93] \\
\hline $\mathrm{H} 13$ & 0.35 & - & 5 & - & 0.35 & 1.5 & - & - & - & - & 1 & - & 0.818 & $615 \pm 35$ & [95] \\
\hline ER70S-6 & 0.1 & - & 0.15 & - & 1.62 & 0.15 & 0.15 & 0.025 & 1 & - & 0.03 & - & 0.237 & $184 \pm 15$ & [96] \\
\hline M2 steel & 0.86 & - & 1.25 & - & 0.37 & 5.23 & - & - & 0.33 & - & - & 6.32 & 1.301 & $800 \pm 100$ & [97] \\
\hline FeCrMoVCtool steel & 0.99 & - & 4.02 & - & - & 7.97 & - & - & - & - & 2.01 & - & 1.923 & $900 \pm 12$ & [98] \\
\hline
\end{tabular}

$\ddagger$ Converted from HRC to HV using Equation (4). 


\subsection{Aluminum Alloys}

Aluminum alloys offer great opportunity for producing lightweight parts for aerospace and automotive applications. As pure aluminum is a relatively soft metal, these alloys often rely on alloying elements to achieve higher strength and hardness through solid solution strengthening and work hardening, such as in 5xxx series alloys, or precipitation hardening, as in the 6xxx and 7xxx series.

A constrained multi-variate linear regression analysis is used for determining the dependence of as-deposited hardness on composition for the AM of aluminum alloys. The following relationship between experimentally measured HV values and chemical composition was obtained where each element is in weight percent:

$$
\mathrm{HV}=37.99+19.47 \mathrm{Ag}+2.85 \mathrm{Cu}+23.36 \mathrm{Fe}+24.47 \mathrm{Mg}+30.00 \mathrm{Mn}+5.43 \mathrm{Si}+20.86 \mathrm{Ti}+19.06 \mathrm{Zn}
$$

The correlation presented is valid for the following ranges of alloying elements: $0-0.5 \mathrm{wt} \% \mathrm{Ag}$, 0-5.3 wt \% Cu, 0-0.8 wt \% Fe, 0-1.95 wt \% Mg, 0-0.55 wt \% Mn, 0-12.2 wt \% Si, 0-0.064 wt \% Ti and $0-0.1 \mathrm{wt} \% \mathrm{Zn}$. The data points with alloying elements that were well outside of the valid ranges mentioned above were omitted. The relationship between the measured hardness and the hardness calculated using Equation (5) for AM data [100-108] is shown in Figure 27. The solid line in the plot is the one-to-one relationship between measured and calculated values, meaning that a point falling on this line is exactly predicted by Equation (5). The chemical compositions are shown in Table 5.

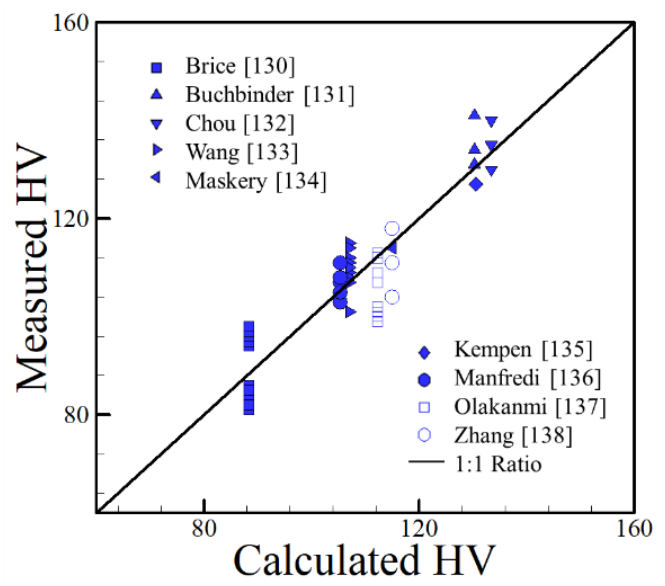

Figure 27. Experimentally measured [100-108] and calculated HV of aluminum alloys fabricated by AM using Equation (5).

Table 5. Compositions (in wt \%) and HV ranges used for aluminum-based alloys.

\begin{tabular}{ccccccccccc}
\hline Alloy & Ag & Cu & Fe & Mg & Mn & Si & Ti & Zn & HV & Ref. \\
\hline Al 2139 & 0.5 & 5.3 & 0.08 & 0.52 & 0.31 & 0.051 & 0.064 & - & $81-103$ & {$[100]$} \\
AlSi10Mg & - & - & 0.55 & 0.4 & 0.45 & 10 & - & 0.1 & $131-141$ & {$[101]$} \\
Al-12Si & - & 0.3 & 0.8 & 0.1 & 0.15 & 12 & - & 0.2 & $130-140$ & {$[102]$} \\
Al-12Si & - & 0.003 & 0.12 & - & - & 12.2 & - & - & $107-115$ & {$[103]$} \\
AlSi10Mg & - & 0.05 & 0.25 & 0.4 & 0.1 & 10 & 0.1 & 0.1 & 114 & {$[104]$} \\
AlSi10Mg & - & 0.1 & 0.55 & 0.4 & 0.45 & 10 & - & 0.1 & 127 & {$[105]$} \\
AlSi10Mg & - & 0.001 & 0.16 & 0.35 & 0.002 & 10.08 & 0.01 & 0.002 & $103-111$ & {$[106]$} \\
Al-12Si & - & 0.08 & 0.36 & - & - & 12.1 & - & - & $99-113$ & {$[107]$} \\
Al 2024 & - & 4.47 & - & 1.95 & 0.55 & - & - & - & $104-118$ & {$[108]$} \\
\hline
\end{tabular}

\subsection{Nickel Alloys}

Nickel alloys are sought after for their excellent high temperature properties and corrosion resistance. Often, alloying elements can account for nearly $50 \%$ of the total weight of the alloy. 
Many nickel alloys are age-hardenable and under the appropriate heat treatment, they can exhibit numerous equilibrium phases consisting of solid solutions, intermetallic compounds and fine precipitates. However, it is often found that due to the high cooling rates encountered during AM, insufficient time is given for these secondary phases to nucleate and grow and many major alloying elements can remain in solid solution [15].

A form of the nickel equivalent [229] is adopted, which is used as a guide for predicting austenite stability during high cooling rate processes, such as welding. The expression used is given as:

$$
\mathrm{Ni}_{\mathrm{EQ}}=\mathrm{Ni}+0.65 \mathrm{Cr}+0.98 \mathrm{Mo}+1.05 \mathrm{Mn}+0.35 \mathrm{Si}+12.6 \mathrm{C}
$$

where all elements are given in weight percentage. To include other alloying elements, a linear regression analysis can be applied to the remainder of elements that are not included in the $\mathrm{Ni}_{\mathrm{EQ}}$ expression. The final term, which will be denoted as $\varphi$, can be expressed as:

$$
\varphi=\mathrm{Ni}_{\mathrm{EQ}}-6.36 \mathrm{Al}+3.80 \mathrm{~B}+0.01 \mathrm{Co}+0.26 \mathrm{Fe}+7.06 \mathrm{Hf}+1.20 \mathrm{Nb}+4.95 \mathrm{Ta}+5.78 \mathrm{Ti}+2.88 \mathrm{~W}
$$

where all elements are given in weight percentage. The expression is valid in the following range of elements: 0-6.5 wt \% Al, 0-3.75 wt \% B, 0-0.5 wt \% C, 0-19.2 wt \% Co, 0-21.8 wt \% Cr, 0-24.7 wt \% Fe, 0-1.5 wt \% Hf, 0-0.48 wt \% Mn, 0-9.75 wt \% Mo, 0-5.1 wt \% Nb, 0-4.25 wt \% Si, 0-6.35 wt \% Ta, 0-4.7 wt \% Ti and 0-4.9 wt \% W. The compositions and HV values used are shown in Table 6. Only elements which either were common to the majority of the alloys considered or contributed to a significant portion of the alloy composition were considered in the analysis as they had negligible effects on the outcome. When independent HV measurements $[67,109-125]$ are plotted against $\varphi$ for various nickel alloys, the trend is linear as shown in Figure 28.

\begin{tabular}{|c|c|c|c|c|c|c|c|c|c|c|c|c|}
\hline Alloy & Al & Co & $\mathrm{Cr}$ & Fe & Mo & $\mathrm{Nb}$ & Si & $\mathbf{T i}$ & C & Other & HV & Ref. \\
\hline IN718 & 0.5 & 1.0 & 19.0 & 22.0 & 3.0 & 5.0 & - & 1.0 & - & - & $387-398$ & [109] \\
\hline IN718 & 0.5 & - & 19.0 & 22.0 & 3.0 & 5.0 & - & 1.0 & - & - & 255 & [110] \\
\hline IN718 & 0.3 & - & 18.4 & 17.7 & 4.2 & 5.1 & - & 0.9 & 0.08 & - & $331.9-395.8$ & [67] \\
\hline Rene 142 & 6.15 & 12.0 & 6.8 & - & 1.5 & 5.1 & - & 0.9 & 0.12 & $\begin{array}{c}0.02 \mathrm{~B}-1.5 \mathrm{Hf} \\
-6.35 \mathrm{Ta}-4.9 \mathrm{~W}\end{array}$ & 428.1 & [111] \\
\hline Colmonoy 6 & - & 0.24 & 13.6 & 4.75 & - & - & 4.25 & - & 0.6 & $2.5 \mathrm{~B}$ & $700-800$ & [112] \\
\hline IN625 & 0.4 & 1.0 & 21.3 & 5.0 & 9.2 & 1.8 & 0.5 & 0.4 & 0.1 & $1.8 \mathrm{Ta}$ & $\ddagger 474.9-574.1$ & [113] \\
\hline Rene 142 & 3.0 & 9.5 & 14.0 & 0.1 & 3.8 & 0.03 & 0.01 & 5.0 & 0.14 & $\begin{array}{c}0.02 \mathrm{~B}-0.01 \mathrm{Hf} \\
-0.01 \mathrm{Mn}-0.01 \mathrm{Ta}\end{array}$ & $410-460$ & [114] \\
\hline Nimonic 263 & 0.5 & 19.2 & 19.5 & 0.5 & 6.0 & - & 0.2 & 2.4 & - & - & 300 & [115] \\
\hline IN718 & 0.29 & - & 18.2 & 18.9 & 3.1 & 5.1 & - & 0.9 & 0.03 & - & $340-380$ & [116] \\
\hline Experimental & - & - & 9.4 & 2.0 & - & - & 2.8 & - & 0.4 & $1.8 \mathrm{~B}$ & $650-800$ & [117] \\
\hline IN718 & 0.41 & - & 15.9 & 17.1 & 1.9 & 2.23 & - & 1.27 & - & $0.31 \mathrm{~W}$ & $400-450$ & [118] \\
\hline IN939 & 1.9 & 19.0 & 22.4 & - & - & 1.0 & - & 3.7 & 0.15 & $0.01 \mathrm{~B}-1.4 \mathrm{Ta}-2.0 \mathrm{~W}$ & 450 & [119] \\
\hline IN718 & - & - & 19.0 & 24.7 & 3.0 & - & 0.35 & - & 0.08 & $0.35 \mathrm{Mn}$ & 245-287 & [120] \\
\hline Rene 41 & 1.6 & 11.0 & 19.0 & 5.0 & 9.75 & - & 0.5 & 3.25 & 0.09 & $0.01 \mathrm{~B}-0.5 \mathrm{Mn}$ & $418.1-435.1$ & [121] \\
\hline Rene 80 & 3.0 & 9.0 & 14.0 & - & 4.0 & - & - & 4.7 & 0.16 & $0.02 \mathrm{~B}-0.8 \mathrm{Hf}$ & 489.8 & [122] \\
\hline Hastelloy X & - & 1.77 & 21.8 & 18.6 & 9.4 & - & 0.31 & - & 0.05 & $0.22 \mathrm{Mn}-1.05 \mathrm{~W}$ & $276.9-284.9$ & [123] \\
\hline Hastelloy X & - & 1.04 & 21.3 & 19.5 & 9.0 & - & 0.32 & - & 0.06 & $0.48 \mathrm{Mn}-0.56 \mathrm{~W}$ & $273.2-281.0$ & [123] \\
\hline IN718 & - & - & 18.3 & 18.9 & 2.0 & 4.6 & - & 0.83 & - & - & $410.8-430.2$ & [124] \\
\hline Ni60A & - & - & 16.5 & 8.0 & - & - & 4.25 & - & 0.75 & $3.75 \mathrm{~B}$ & $\ddagger 631.1-762.9$ & [125] \\
\hline
\end{tabular}

Table 6. Compositions (in wt \%) and range of HV numbers for nickel alloys.

$\ddagger$ Converted from HRC to HV using Equation (4). 


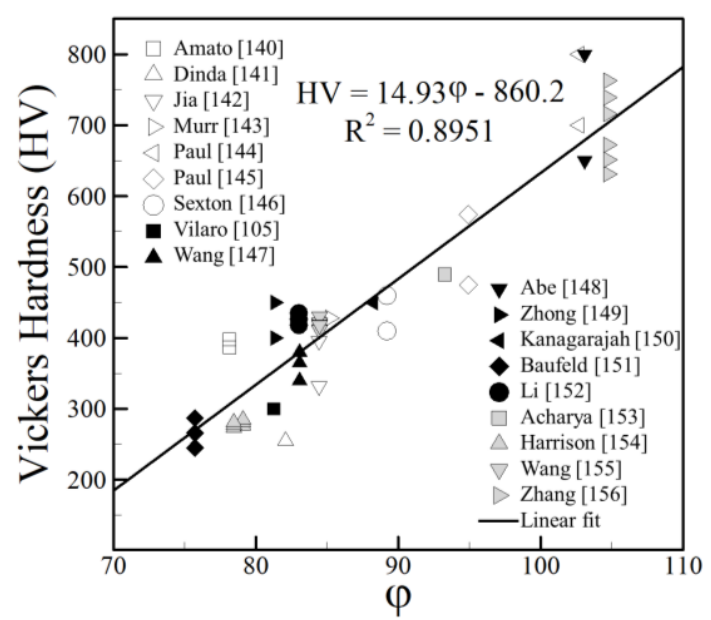

Figure 28. As-deposited HV [67,109-125] as a function of $\varphi$, which depends on the chemical composition of nickel-based AM alloys. Reprinted from [17] with permission from Elsevier.

\subsection{Comparison with Other Processes}

It is often useful to compare microstructures and properties with the cooling rates of various processes. Since AM is a rapidly emerging field and the underlying science is still being understood, it can be beneficial to compare the hardness of AM alloys with measurements from other processes. Let us consider fusion welding, where melting is used for joining and friction stir welding (FSW), a process where solidification is not involved and joining is performed in solid state. To understand the relative role of manufacturing process variables and the chemical composition of steels, Figure 29 combines hardness data for steels from AM, FSW and fusion welding literature. Table 4 shows the specific compositions for AM while the compositions and hardness values for FSW and fusion welding can be found elsewhere $[226,230,231]$. To give the reader a sense of the cooling rates, Table 7 shows a collection of available data for cooling rates measured in the three processes. There are many orders of magnitude difference between the processes, ranging from reported values of $3 \mathrm{~K} / \mathrm{s}$ for friction stir welding to $10^{4} \mathrm{~K} / \mathrm{s}$ for $\mathrm{AM}$.

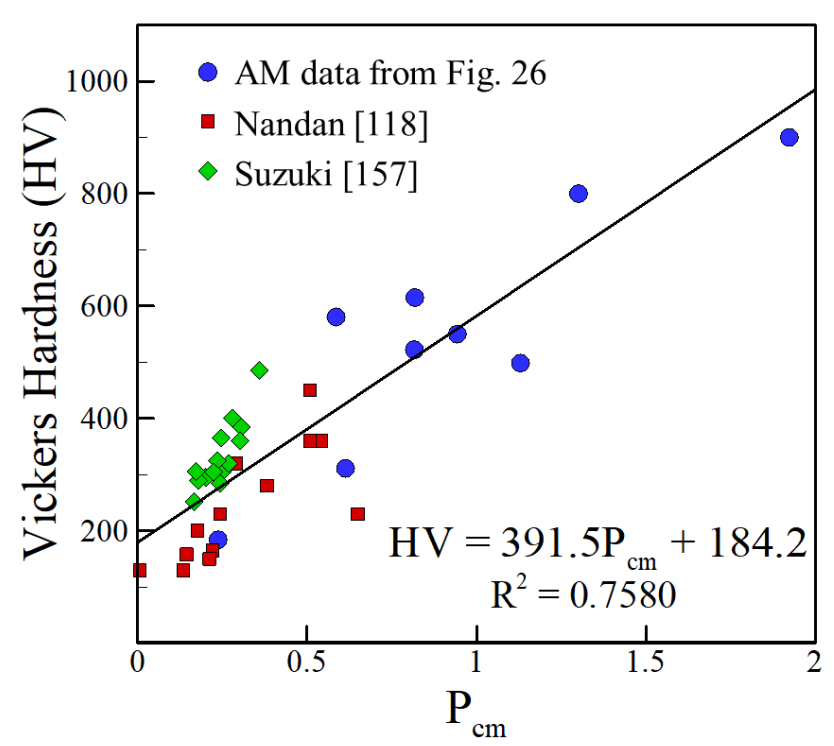

Figure 29. Comparison between measured as-deposited hardness values of iron-based alloys in AM, TMAZ hardness values of FSW and as-welded hardness from fusion welding. 
Table 7. Reported cooling rates for FSW, fusion welding and AM.

\begin{tabular}{ccc}
\hline Process & Values/Ranges $\mathbf{( K / s )}$ & Reference \\
\hline FSW & $\sim 5$ & {$[232]$} \\
FSW & $\sim 3$ to 5 & {$[233]$} \\
FSW & $\sim 90$ to 120 & {$[234]$} \\
FSW & $\sim 10$ & {$[235]$} \\
Submerged FSW & $\sim 20$ & {$[236]$} \\
Fusion welding & $\sim 5$ & {$[237]$} \\
Laser welding & $10^{0}$ to $10^{5}$ & {$[238]$} \\
Fusion welding & $\sim 10^{3}$ & {$[227]$} \\
DED-L & 4500 & {$[239]$} \\
PBF-L & $10^{3}$ to $10^{4}$ & {$[197]$} \\
DED-L & $10^{4}$ & {$[240]$} \\
DED-L & $\sim 10^{3}-10^{4}$ & {$[9]$} \\
PBF-L & $1.0 \times 10^{6}$ to $4.0 \times 10^{7}$ & {$[241]$} \\
\hline
\end{tabular}

Similar analyses for the hardness of steels in the thermo-mechanically affected zone (TMAZ) of FSW and the heat affected zone (HAZ) of fusion welding were presented by Nandan et al. [226] and Suzuki [230]. When comparing their work to Figure 29, striking similarities are observed. Combining the data from AM, FSW and fusion welding, the HV of steels is linearly dependent on $P_{c m}$ with $R^{2}=0.7580$, which is slightly lower than the value of $R^{2}=0.7632$ obtained for only AM data alone indicating consistency in the relationships. Figure 29 shows that when hardness is calculated for the TMAZ of FSW and the HAZ of fusion welding using Equation (3), a good correlation with a trend consistent to the AM data is obtained. It is important to note that the data from Ito and Bessyo [231] for which $\mathrm{P}_{\mathrm{cm}}$ was originally derived for was clustered around small $\mathrm{P}_{\mathrm{cm}}$ values of less than 0.4 that resulted in a large slope of the $\mathrm{P}_{\mathrm{cm}}$ versus HV plot as shown by Suzuki [230]. As this work extends to a much broader range of $P_{\mathrm{cm}}$ values up to almost 2, a smaller slope is obtained. These findings show that the presented approximations can be applied to three different types of joining processes while still producing consistent results, highlighting the important role of composition for predicting hardness of steels.

Data for the measured and predicted as-deposited hardness of FSW aluminum alloys is also compared to AM data in Figure 30. A similar plot for the hardness of aluminum alloys were presented by Arora et al. [242] for the FSW of aluminum alloys. Figure 30 shows that when as-welded hardness is calculated for the TMAZ of FSW using Equation (5), a good correlation with a trend consistent to the AM data is obtained. These findings show that Equation (5) can be applied to both AM and FSW while ignoring process variables and is still capable of producing approximate hardness values, signifying the importance of chemical composition in determining the hardness of aluminum alloys. For the FSW data, $\mathrm{Mg}$ and $\mathrm{Zn}$ were important alloying elements for the alloys considered, which is not the case here.

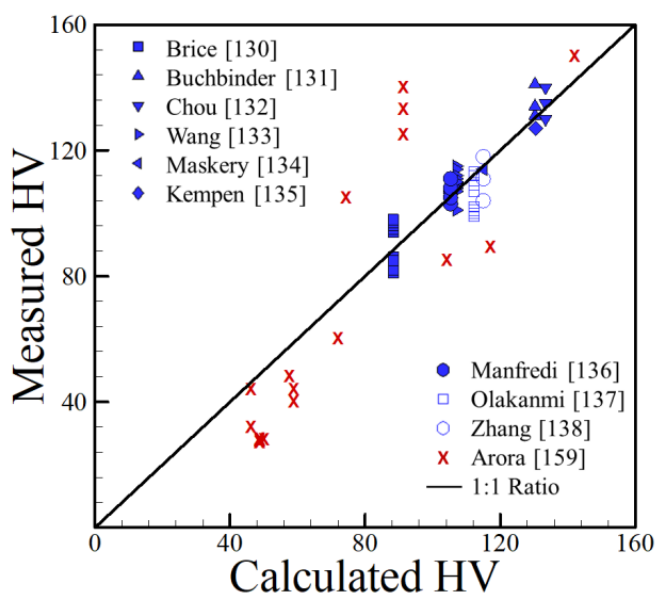

Figure 30. Comparison between measured and calculated hardness values using Equation (5) for AM and FSW data [242]. 


\section{Concluding Remarks}

The role of cooling rate, microstructure and alloy composition on the published hardness data of iron, aluminum, titanium and nickel alloy components fabricated by AM are examined. The correlations presented in this review provide a useful and practical means of obtaining an approximate value of hardness of AM alloys by conducting back-of-the envelope calculations. When the available data are critically reviewed, the following important conclusions that cannot be made from individual papers become apparent.

(a) The variations of process parameters and cooling rates change microstructures of AM alloys. However, when the influence of AM process parameters on hardness is evaluated from the reported independent hardness values of fabricated components prior to post-deposition heat treatment, the variation of hardness falls within a narrow band of values for ferrous, aluminum and nickel alloys.

(b) The range of hardness variation of AM alloys in the as-fabricated state attainable by varying AM process parameters is much lower than the hardness enhancement attainable by subsequent heat treatment or aging. The extent of hardness variation by varying AM process variables is roughly the same as the reported variations of hardness of iron and aluminum alloy weld metals when welding parameters are varied.

(c) The reported hardness data show approximate linear trends with appropriate compositional variables for iron, aluminum and nickel alloys over a wide range of AM variables and processes. The scatter in the hardness data for all alloy systems fall within a small band of values that correlates well with the concentration of alloying elements. The correlations developed are approximate and valid for the range of composition indicated but the findings are consistent over a wide range of processes and process parameters.

(d) Although AM offers many advantages in fabricating metallic components, a target hardness of components in as fabricated condition is much more easily obtained by alloy selection rather than by changing AM processing variables. In this sense, the AM produced materials behave in a manner similar to other conventional metals processing technologies.

Author Contributions: Conceptualization, J.S.Z. and T.D.; Writing-Original Draft Preparation, J.S.Z. and T.D.; Writing-Review \& Editing, J.S.Z. and T.D.; Supervision, T.D.; Project Administration, T.D.; Funding Acquisition, T.D.

Funding: The authors would like to acknowledge the financial support provided by the US Department of Energy NEUP Grant DE-NE0008280.

Conflicts of Interest: The authors declare no conflict of interest.

\section{References}

1. Keist, J.S.; Palmer, T.A. evelopment of strength-hardness relationships in additively manufactured titanium alloys. Mater. Sci. Eng. A 2017, 693, 214-224. [CrossRef]

2. Attar, H.; Ehtemam-Haghighi, S.; Kent, D.; Okulov, I.V.; Wendrock, H.; Bönisch, M.; Volegov, A.S.; Calin, M.; Eckert, J.; Dargusch, M.S. Nanoindentation and wear properties of Ti and Ti-TiB composite materials produced by selective laser melting. Mater. Sci. Eng. A 2017, 688, 20-26. [CrossRef]

3. Baufeld, B. Effect of deposition parameters on mechanical properties of shaped metal deposition parts. Proc. Inst. Mech. Eng. B J. Eng. 2012, 226, 126-136. [CrossRef]

4. Wang, Z.; Palmer, T.A.; Beese, A.M. Effect of processing parameters on microstructure and tensile properties of austenitic stainless steel 304L made by directed energy deposition additive manufacturing. Acta Mater. 2016, 110, 226-235. [CrossRef]

5. Mertens, R.; Clijsters, S.; Kempen, K.; Kruth, J.P. Optimization of scan strategies in Selective laser melting of aluminum parts with downfacing areas. J. Manuf. Sci. Eng. 2014, 136, 061012. [CrossRef]

6. Kruth, J.P.; Froyen, L.; Van Vaerenbergh, J.; Mercelis, P.; Rombouts, M.; Lauwers, B. Selective laser melting of iron-based powder. J. Mater. Process. Technol. 2004, 149, 616-622. [CrossRef] 
7. Mukherjee, T.; Manvatkar, V.; De, A.; DebRoy, T. Mitigation of thermal distortion during additive manufacturing. Scr. Mater. 2017, 127, 79-83. [CrossRef]

8. Manvatkar, V.; De, A.; DebRoy, T. Spatial variation of melt pool geometry, peak temperature and solidification parameters during laser assisted additive manufacturing process. Mater. Sci. Technol. 2015, 31, 924-930. [CrossRef]

9. Manvatkar, V.; De, A.; DebRoy, T. Heat transfer and material flow during laser assisted multi-layer additive manufacturing. J. Appl. Phys. 2014, 116, 124905. [CrossRef]

10. Mukherjee, T.; Zuback, J.; De, A.; DebRoy, T. Printability of alloys for additive manufacturing. Sci. Rep. 2016, 6, 19717. [CrossRef] [PubMed]

11. Raghavan, A.; Wei, H.L.; Palmer, T.A.; DebRoy, T. Heat transfer and fluid flow in additive manufacturing. J. Laser Appl. 2013, 25, 052006. [CrossRef]

12. Wei, H.; Mazumder, J.; DebRoy, T. Evolution of solidification texture during additive manufacturing. Sci. Rep. 2015, 5, 16446. [CrossRef] [PubMed]

13. Leuders, S.; Thöne, M.; Riemer, A.; Niendorf, T.; Tröster, T.; Richard, H.; Maier, H. On the mechanical behaviour of titanium alloy TiAl6V4 manufactured by selective laser melting: Fatigue resistance and crack growth performance. Int. J. Fatigue 2013, 48, 300-307. [CrossRef]

14. Zhao, X.; Lin, X.; Chen, J.; Xue, L.; Huang, W. The effect of hot isostatic pressing on crack healing, microstructure, mechanical properties of Rene88DT superalloy prepared by laser solid forming. Mater. Sci. Eng. A 2009, 504, 129-134. [CrossRef]

15. Jägle, E.A.; Sheng, Z.; Wu, L.; Lu, L.; Risse, J.; Weisheit, A.; Raabe, D. Precipitation reactions in age-hardenable alloys during laser additive manufacturing. JOM 2016, 68, 943-949. [CrossRef]

16. Beese, A.M.; Carroll, B.E. Review of mechanical properties of Ti-6Al-4V made by laser-based additive manufacturing using powder feedstock. JOM 2016, 68, 724-734. [CrossRef]

17. DebRoy, T.; Wei, H.; Zuback, J.; Mukherjee, T.; Elmer, J.; Milewski, J.; Beese, A.; Wilson-Heid, A.; De, A.; Zhang, W. Additive manufacturing of metallic components-process, structure and properties. Prog. Mater. Sci. 2018, 92, 112-224. [CrossRef]

18. Lewandowski, J.J.; Seifi, M. Metal additive manufacturing: A review of mechanical properties. Ann. Rev. Mater. Res. 2016, 46, 151-186. [CrossRef]

19. Gorsse, S.; Hutchinson, C.; Gouné, M.; Banerjee, R. Additive manufacturing of metals: A brief review of the characteristic microstructures and properties of steels, Ti-6Al-4V and high-entropy alloys. Sci. Technol. Adv. Mater. 2017, 18, 584-610. [CrossRef] [PubMed]

20. Gu, D.D.; Meiners, W.; Wissenbach, K.; Poprawe, R. Laser additive manufacturing of metallic components: Materials, processes and mechanisms. Int. Mater. Rev. 2012, 57, 133-164. [CrossRef]

21. Sames, W.J.; List, F.; Pannala, S.; Dehoff, R.R.; Babu, S.S. The metallurgy and processing science of metal additive manufacturing. Int. Mater. Rev. 2016, 61, 315-360. [CrossRef]

22. Frazier, W.E. Metal additive manufacturing: A review. J. Mater. Eng. Perform. 2014, 23, 1917-1928. [CrossRef]

23. Murr, L.E.; Gaytan, S.M.; Ramirez, D.A.; Martinez, E.; Hernandez, J.; Amato, K.N.; Shindo, P.W.; Medina, F.R.; Wicker, R.B. Metal fabrication by additive manufacturing using laser and electron beam melting technologies. J. Mater. Sci. Technol. 2012, 28, 1-14. [CrossRef]

24. Körner, C. Additive manufacturing of metallic components by selective electron beam melting-A review. Int. Mater. Rev. 2016, 61, 361-377. [CrossRef]

25. Yap, C.; Chua, C.; Dong, Z.; Liu, Z.; Zhang, D.; Loh, L.; Sing, S. Review of selective laser melting: Materials and applications. Appl. Phys. Rev. 2015, 2, 041101. [CrossRef]

26. Herzog, D.; Seyda, V.; Wycisk, E.; Emmelmann, C. Additive manufacturing of metals. Acta Mater. 2016, 117, 371-392. [CrossRef]

27. Zhang, D.; Sun, S.; Qiu, D.; Gibson, M.A.; Dargusch, M.S.; Brandt, M.; Qian, M.; Easton, M. Metal alloys for fusion-based additive manufacturing. Adv. Eng. Mater. 2018. [CrossRef]

28. Yan, W.; Lin, S.; Kafka, O.L.; Yu, C.; Liu, Z.; Lian, Y.; Wolff, S.; Cao, J.; Wagner, G.J.; Liu, W.K. Modeling process-structure-property relationships for additive manufacturing. Front. Mech. Eng. 2018, 13, 482-492. [CrossRef]

29. Cao, F.; Zhang, T.; Ryder, M.A.; Lados, D.A. A review of the fatigue properties of additively manufactured Ti-6Al-4V. JOM 2018, 70, 349-357. [CrossRef] 
30. Kok, Y.; Tan, X.P.; Wang, P.; Nai, M.; Loh, N.H.; Liu, E.; Tor, S.B. Anisotropy and heterogeneity of microstructure and mechanical properties in metal additive manufacturing: A critical review. Mater. Des. 2018, 139, 565-586. [CrossRef]

31. Agius, D.; Kourousis, K.I.; Wallbrink, C. A review of the as-built SLM Ti-6Al-4V mechanical properties towards achieving fatigue resistant designs. Metals 2018, 8, 75. [CrossRef]

32. Yusuf, S.M.; Gao, N. Influence of energy density on metallurgy and properties in metal additive manufacturing. Mater. Sci. Technol. 2017, 33, 1269-1289. [CrossRef]

33. Easton, M.; Qian, M.; Prasad, A.; StJohn, D. Recent advances in grain refinement of light metals and alloys. Curr. Opin. Solid State Mater. Sci. 2016, 20, 13-24. [CrossRef]

34. Collins, P.; Brice, D.; Samimi, P.; Ghamarian, I.; Fraser, H. Microstructural control of additively manufactured metallic materials. Ann. Rev. Mater. Res. 2016, 46, 63-91. [CrossRef]

35. Derekar, K. A review of wire arc additive manufacturing and advances in wire arc additive manufacturing of aluminium. Mater. Sci. Technol. 2018, 34, 1-22. [CrossRef]

36. Shipley, H.; McDonnell, D.; Culleton, M.; Lupoi, R.; O’Donnell, G.; Trimble, D. Optimisation of process parameters to address fundamental challenges during selective laser melting of Ti-6Al-4V: A review. Int. J. Mach. Tools Manuf. 2018, 128, 1-20. [CrossRef]

37. Hitzler, L.; Merkel, M.; Hall, W.; Öchsner, A. A review of metal fabricated with laser-and powder-bed based additive manufacturing techniques: Process, nomenclature, materials, achievable properties and its utilization in the medical sector. Adv. Eng. Mater. 2018, 20, 1700658. [CrossRef]

38. Zhang, L.C.; Liu, Y.; Li, S.; Hao, Y. Additive manufacturing of titanium alloys by electron beam melting: A review. Adv. Eng. Mater. 2018, 20, 1700842. [CrossRef]

39. Song, B.; Zhao, X.; Li, S.; Han, C.; Wei, Q.; Wen, S.; Liu, J.; Shi, Y. Differences in microstructure and properties between selective laser melting and traditional manufacturing for fabrication of metal parts: A review. Front. Mech. Eng. 2015, 10, 111-125. [CrossRef]

40. Shamsaei, N.; Yadollahi, A.; Bian, L.; Thompson, S.M. An overview of Direct Laser Deposition for additive manufacturing; Part II: Mechanical behavior, process parameter optimization and control. Addit. Manuf. 2015, 8, 12-35. [CrossRef]

41. Trevisan, F.; Calignano, F.; Lorusso, M.; Pakkanen, J.; Aversa, A.; Ambrosio, E.P.; Lombardi, M.; Fino, P.; Manfredi, D. On the selective laser melting (SLM) of the AlSi10Mg alloy: Process, microstructure and mechanical properties. Materials 2017, 10, 76. [CrossRef] [PubMed]

42. Wang, X.; Gong, X.; Chou, K. Review on powder-bed laser additive manufacturing of Inconel 718 parts. Proc. Inst. Mech. Eng. B J. Eng. 2017, 231, 1890-1903. [CrossRef]

43. Yan, M.; Xu, W.; Dargusch, M.; Tang, H.; Brandt, M.; Qian, M. Review of effect of oxygen on room temperature ductility of titanium and titanium alloys. Powder Metall. 2014, 57, 251-257. [CrossRef]

44. Saboori, A.; Gallo, D.; Biamino, S.; Fino, P.; Lombardi, M. An overview of additive manufacturing of titanium components by directed energy deposition: Microstructure and mechanical properties. Appl. Sci. 2017, 7, 883. [CrossRef]

45. Zhang, K.; Wang, S.; Liu, W.; Shang, X. Characterization of stainless steel parts by laser metal deposition shaping. Mater. Des. 2014, 55, 104-119. [CrossRef]

46. Yu, J.; Rombouts, M.; Maes, G. Cracking behavior and mechanical properties of austenitic stainless steel parts produced by laser metal deposition. Mater. Des. 2013, 45, 228-235. [CrossRef]

47. Li, J.; Deng, D.; Hou, X.; Wang, X.; Ma, G.; Wu, D.; Zhang, G. Microstructure and performance optimisation of stainless steel formed by laser additive manufacturing. Mater. Sci. Technol. 2016, 32, 1223-1230. [CrossRef]

48. Ziętala, M.; Durejko, T.; Polański, M.; Kunce, I.; Płociński, T.; Zieliński, W.; Łazińska, M.; Stępniowski, W.; Czujko, T.; Kurzydłowski, K.J.; et al. The microstructure, mechanical properties and corrosion resistance of 316L stainless steel fabricated using laser engineered net shaping. Mater. Sci. Eng. A 2016, 677, 1-10. [CrossRef]

49. Ma, M.; Wang, Z.; Wang, D.; Zeng, X. Control of shape and performance for direct laser fabrication of precision large-scale metal parts with 316L Stainless Steel. Opt. Laser Technol. 2013, 45, 209-216. [CrossRef]

50. Abd-Elghany, K.; Bourell, D.L. Property evaluation of 304L stainless steel fabricated by selective laser melting. Rapid Prototyp. J. 2012, 18, 420-428. [CrossRef] 
51. Tolosa, I.; Garciandia, F.; Zubiri, F.; Zapirain, F.; Esnaola, A. Study of mechanical properties of AISI 316 stainless steel processed by "selective laser melting", following different manufacturing strategies. Int. J. Adv. Manuf. Technol. 2010, 51, 639-647. [CrossRef]

52. Sun, Z.; Tan, X.; Tor, S.B.; Yeong, W.Y. Selective laser melting of stainless steel 316L with low porosity and high build rates. Mater. Des. 2016, 104, 197-204. [CrossRef]

53. Knapp, G.L.; Mukherjee, T.; Zuback, J.S.; Wei, H.L.; Palmer, T.A.; De, A.; DebRoy, T. Building blocks for a digital twin of additive manufacturing. Acta Mater. 2017, 135, 390-399. [CrossRef]

54. Galarraga, H.; Lados, D.A.; Dehoff, R.R.; Kirka, M.M.; Nandwana, P. Effects of the microstructure and porosity on properties of Ti-6Al-4V ELI alloy fabricated by electron beam melting (EBM). Addit. Manuf. 2016, 10, 47-57. [CrossRef]

55. Brandl, E.; Baufeld, B.; Leyens, C.; Gault, R. Additive manufactured Ti-6Al-4V using welding wire: Comparison of laser and arc beam deposition and evaluation with respect to aerospace material specifications. Phys. Procedia 2010, 5, 595-606. [CrossRef]

56. Brandl, E.; Schoberth, A.; Leyens, C. Morphology, microstructure and hardness of titanium (Ti-6Al-4V) blocks deposited by wire-feed additive layer manufacturing (ALM). Mater. Sci. Eng. A 2012, 532, 295-307. [CrossRef]

57. Carroll, B.E.; Palmer, T.A.; Beese, A.M. Anisotropic tensile behavior of Ti-6Al-4V components fabricated with directed energy deposition additive manufacturing. Acta Mater. 2015, 87, 309-320. [CrossRef]

58. Zhu, Y.; Li, J.; Tian, X.; Wang, H.; Liu, D. Microstructure and mechanical properties of hybrid fabricated Ti-6.5 Al-3.5 Mo-1.5 Zr-0.3 Si titanium alloy by laser additive manufacturing. Mater. Sci. Eng. A 2014, 607, 427-434. [CrossRef]

59. Vrancken, B.; Thijs, L.; Kruth, J.P.; Van Humbeeck, J. Microstructure and mechanical properties of a novel $\beta$ titanium metallic composite by selective laser melting. Acta Mater. 2014, 68, 150-158. [CrossRef]

60. Baufeld, B.; Van der Biest, O. Mechanical properties of Ti-6Al-4V specimens produced by shaped metal deposition. Sci. Technol. Adv. Mater. 2009, 10, 015008. [CrossRef] [PubMed]

61. Abe, F.; Osakada, K.; Kitamura, Y.; Matsumoto, M.; Shiomi, M. Manufacturing of titanium parts for medical purposes by selective laser melting. In Proceedings of the 8th International Conference Rapid Prototyping, Tokyo, Japan, 12-13 June 2000; pp. 288-293.

62. Hrabe, N.; Quinn, T. Effects of processing on microstructure and mechanical properties of a titanium alloy (Ti-6Al-4V) fabricated using electron beam melting (EBM), Part 2: Energy input, orientation and location. Mater. Sci. Eng. A 2013, 573, 271-277. [CrossRef]

63. Attar, H.; Calin, M.; Zhang, L.C.; Scudino, S.; Eckert, J. Manufacture by selective laser melting and mechanical behavior of commercially pure titanium. Mater. Sci. Eng. A 2014, 593, 170-177. [CrossRef]

64. Murr, L.E.; Gaytan, S.M.; Ceylan, A.; Martinez, E.; Martinez, J.L.; Hernandez, D.H.; Machado, B.I.; Ramirez, D.A.; Medina, F.; Collins, S.; et al. Characterization of titanium aluminide alloy components fabricated by additive manufacturing using electron beam melting. Acta Mater. 2010, 58, 1887-1894. [CrossRef]

65. Schwab, H.; Prashanth, K.; Löber, L.; Kühn, U.; Eckert, J. Selective Laser Melting of Ti-45Nb Alloy. Metals 2015, 5, 686. [CrossRef]

66. Cherry, J.A.; Davies, H.M.; Mehmood, S.; Lavery, N.P.; Brown, S.G.R.; Sienz, J. Investigation into the effect of process parameters on microstructural and physical properties of 316L stainless steel parts by selective laser melting. Int. J. Adv. Manuf. Technol. 2015, 76, 869-879. [CrossRef]

67. Jia, Q.B.; Gu, D.D. Selective laser melting additive manufacturing of Inconel 718 superalloy parts: Densification, microstructure and properties. J. Alloys Compd. 2014, 585, 713-721. [CrossRef]

68. Thijs, L.; Verhaeghe, F.; Craeghs, T.; Van Humbeeck, J.; Kruth, J.-P. A study of the microstructural evolution during selective laser melting of Ti-6Al-4V. Acta Mater. 2010, 58, 3303-3312. [CrossRef]

69. Mukherjee, T.; Manvatkar, V.; De, A.; DebRoy, T. Dimensionless numbers in additive manufacturing. J. Appl. Phys. 2017, 121, 064904. [CrossRef]

70. Amine, T.; Newkirk, J.W.; Liou, F. Investigation of effect of process parameters on multilayer builds by direct metal deposition. Appl. Therm. Eng. 2014, 73, 500-511. [CrossRef]

71. Bardelcik, A.; Salisbury, C.P.; Winkler, S.; Wells, M.A.; Worswick, M.J. Effect of cooling rate on the high strain rate properties of boron steel. Int. J. Impact Eng. 2010, 37, 694-702. [CrossRef] 
72. Nishibata, T.; Kojima, N. Effect of quenching rate on hardness and microstructure of hot-stamped steel. J. Alloys Compd. 2013, 577, S549-S554. [CrossRef]

73. Olasolo, M.; Uranga, P.; Rodriguez-Ibabe, J.; López, B. Effect of austenite microstructure and cooling rate on transformation characteristics in a low carbon $\mathrm{Nb}-\mathrm{V}$ microalloyed steel. Mater. Sci. Eng. A 2011, 528, 2559-2569. [CrossRef]

74. Thompson, S.; Col, D.V.; Krauss, G. Continuous cooling transformations and microstructures in a low-carbon, high-strength low-alloy plate steel. Metall. Trans. A 1990, 21, 1493-1507. [CrossRef]

75. Thompson, S.; Colvin, D.; Krauss, G. Austenite decomposition during continuous cooling of an HSLA-80 plate steel. Metall. Mater. Trans. A 1996, 27, 1557-1571. [CrossRef]

76. Qiao, Z.; Liu, Y.; Yu, L.; Gao, Z. Effect of cooling rate on microstructural formation and hardness of 30CrNi3Mo steel. Appl. Phys. A Mater. 2009, 95, 917-922. [CrossRef]

77. Birol, Y. Optimization of homogenization for a low alloyed AlMgSi alloy. Mater. Charact. 2013, 80, 69-75. [CrossRef]

78. Brito, C.; Costa, T.A.; Vida, T.A.; Bertelli, F.; Cheung, N.; Spinelli, J.E.; Garcia, A. Characterization of dendritic microstructure, intermetallic phases and hardness of directionally solidified Al-Mg and Al-Mg-Si alloys. Metall. Mater. Trans. A 2015, 46, 3342-3355. [CrossRef]

79. Çadırlı, E. Effect of solidification parameters on mechanical properties of directionally solidified Al-rich Al-Cu alloys. Met. Mater.-Int. 2013, 19, 411-422. [CrossRef]

80. Cavazos, J.L.; Colás, R. Precipitation in a heat-treatable aluminum alloy cooled at different rates. Mater. Charact. 2001, 47, 175-179. [CrossRef]

81. Zhang, L.; Jiang, Y.; Ma, Z.; Shan, S.; Jia, Y.; Fan, C.; Wang, W. Effect of cooling rate on solidified microstructure and mechanical properties of aluminium-A356 alloy. J. Mater. Process. Technol. 2008, 207, 107-111. [CrossRef]

82. Milenkovic, S.; Sabirov, I.; Llorca, J. Effect of the cooling rate on microstructure and hardness of MAR-M247 Ni-based superalloy. Mater. Lett. 2012, 73, 216-219. [CrossRef]

83. Mitchell, R.; Preuss, M.; Tin, S.; Hardy, M. The influence of cooling rate from temperatures above the $\gamma^{\prime}$ solvus on morphology, mismatch and hardness in advanced polycrystalline nickel-base superalloys. Mater. Sci. Eng. A 2008, 473, 158-165. [CrossRef]

84. Geng, L.; Na, Y.-S.; Park, N.-K. Continuous cooling transformation behavior of alloy 718. Mater. Lett. 1997, 30, 401-405. [CrossRef]

85. Rahimian, M.; Milenkovic, S.; Sabirov, I. Microstructure and hardness evolution in MAR-M247 Ni-based superalloy processed by controlled cooling and double heat treatment. J. Alloys Compd. 2013, 550, 339-344. [CrossRef]

86. Karaköse, E.; Keskin, M. Effect of microstructural evolution and elevated temperature on the mechanical properties of Ni-Cr-Mo alloys. J. Alloys Compd. 2015, 619, 82-90. [CrossRef]

87. Callister, W.D.; Rethwisch, D.G. Materials Science and Engineering; John Wiley \& Sons: Hoboken, NJ, USA, 2011; Volume 5.

88. Farshidianfar, M.H.; Khajepour, A.; Gerlich, A.P. Effect of real-time cooling rate on microstructure in laser additive manufacturing. J. Mater. Process. Technol. 2016, 231, 468-478. [CrossRef]

89. Keist, J.S.; Palmer, T.A. Role of geometry on properties of additively manufactured Ti-6Al-4V structures fabricated using laser based directed energy deposition. Mater. Des. 2016, 106, 482-494. [CrossRef]

90. Tian, Y.; McAllister, D.; Colijn, H.; Mills, M.; Farson, D.; Nordin, M.; Babu, S. Rationalization of microstructure heterogeneity in Inconel 718 builds made by the direct laser additive manufacturing process. Metall. Mater. Trans. A 2014, 45, 4470-4483. [CrossRef]

91. Cormier, D.; Harrysson, A.; West, H. Characterization of H13 steel produced via electron beam melting. Rapid Prototyp. J. 2004, 10, 35-41. [CrossRef]

92. Bhattacharya, S.; Dinda, G.P.; Dasgupta, A.K.; Mazumder, J. Microstructural evolution of AISI 4340 steel during direct metal deposition process. Mater. Sci. Eng. A 2011, 528, 2309-2318. [CrossRef]

93. Casalino, G.; Campanelli, S.L.; Contuzzi, N.; Ludovico, A.D. Experimental investigation and statistical optimisation of the selective laser melting process of a maraging steel. Opt. Laser Technol. 2015, 65, 151-158. [CrossRef]

94. Choi, J.; Chang, Y. Characteristics of laser aided direct metal/material deposition process for tool steel. Int. J. Mach. Tools Manuf. 2005, 45, 597-607. [CrossRef] 
95. Cottam, R.; Wang, J.; Luzin, V. Characterization of microstructure and residual stress in a 3D H13 tool steel component produced by additive manufacturing. J. Mater. Res. 2014, 29, 1978-1986. [CrossRef]

96. Haselhuhn, A.S.; Wijnen, B.; Anzalone, G.C.; Sanders, P.G.; Pearce, J.M. In situ formation of substrate release mechanisms for gas metal arc weld metal 3-D printing. J. Mater. Process. Technol. 2015, 226, 50-59. [CrossRef]

97. Simchi, A.; Asgharzadeh, H. Densification and microstructural evaluation during laser sintering of M2 high speed steel powder. Mater. Sci. Technol. 2004, 20, 1462-1468. [CrossRef]

98. Sander, J.; Hufenbach, J.; Giebeler, L.; Wendrock, H.; Kuhn, U.; Eckert, J. Microstructure and properties of FeCrMoVC tool steel produced by selective laser melting. Mater. Des. 2016, 89, 335-341. [CrossRef]

99. Jamshidinia, M.; Sadek, A.; Wang, W.; Kelly, S. Additive manufacturing of steel alloys using laser powder-bed fusion. Adv. Mater. Process. 2015, 173, 20-24.

100. Brice, C.; Shenoy, R.; Kral, M.; Buchannan, K. Precipitation behavior of aluminum alloy 2139 fabricated using additive manufacturing. Mater. Sci. Eng. A 2015, 648, 9-14. [CrossRef]

101. Buchbinder, D.; Meiners, W.; Pirch, N.; Wissenbach, K.; Schrage, J. Investigation on reducing distortion by preheating during manufacture of aluminum components using selective laser melting. J. Laser Appl. 2014, 26, 012004. [CrossRef]

102. Chou, R.; Milligan, J.; Paliwal, M.; Brochu, M. Additive manufacturing of Al-12Si alloy via pulsed selective laser melting. JOM 2015, 67, 590-596. [CrossRef]

103. Wang, X.J.; Zhang, L.C.; Fang, M.H.; Sercombe, T.B. The effect of atmosphere on the structure and properties of a selective laser melted Al-12Si alloy. Mater. Sci. Eng. A 2014, 597, 370-375. [CrossRef]

104. Maskery, I.; Aboulkhair, N.T.; Corfield, M.R.; Tuck, C.; Clare, A.T.; Leach, R.K.; Wildman, R.D.; Ashcroft, I.A.; Hague, R.J.M. Quantification and characterisation of porosity in selectively laser melted Al-Si10-Mg using X-ray computed tomography. Mater. Charact. 2016, 111, 193-204. [CrossRef]

105. Kempen, K.; Thijs, L.; Van Humbeeck, J.; Kruth, J.-P. Mechanical properties of AlSi10Mg produced by selective laser melting. Phys. Procedia 2012, 39, 439-446. [CrossRef]

106. Manfredi, D.; Calignano, F.; Krishnan, M.; Canali, R.; Ambrosio, E.P.; Atzeni, E. From powders to dense metal parts: Characterization of a commercial AlSiMg alloy processed through direct metal laser sintering. Materials 2013, 6, 856-869. [CrossRef] [PubMed]

107. Olakanmi, E.O.; Cochrane, R.F.; Dalgarno, K.W. Densification mechanism and microstructural evolution in selective laser sintering of Al-12Si powders. J. Mater. Process. Technol. 2011, 211, 113-121. [CrossRef]

108. Zhang, H.; Zhu, H.H.; Qi, T.; Hu, Z.H.; Zeng, X.Y. Selective laser melting of high strength Al-Cu-Mg alloys: Processing, microstructure and mechanical properties. Mater. Sci. Eng. A 2016, 656, 47-54. [CrossRef]

109. Amato, K.N.; Gaytan, S.M.; Murr, L.E.; Martinez, E.; Shindo, P.W.; Hernandez, J.; Collins, S.; Medina, F. Microstructures and mechanical behavior of Inconel 718 fabricated by selective laser melting. Acta Mater. 2012, 60, 2229-2239. [CrossRef]

110. Dinda, G.P.; Dasgupta, A.K.; Mazumder, J. Texture control during laser deposition of nickel-based superalloy. Scr. Mater. 2012, 67, 503-506. [CrossRef]

111. Murr, L.E.; Martinez, E.; Pan, X.M.; Gaytan, S.M.; Castro, J.A.; Terrazas, C.A.; Medina, F.; Wicker, R.B.; Abbott, D.H. Microstructures of Rene 142 nickel-based superalloy fabricated by electron beam melting. Acta Mater. 2013, 61, 4289-4296. [CrossRef]

112. Paul, C.P.; Jain, A.; Ganesh, P.; Negi, J.; Nath, A.K. Laser rapid manufacturing of Colmonoy-6 components. Opt. Laser Eng. 2006, 44, 1096-1109. [CrossRef]

113. Paul, C.P.; Ganesh, P.; Mishra, S.K.; Bhargava, P.; Negi, J.; Nath, A.K. Investigating laser rapid manufacturing for Inconel-625 components. Opt. Laser Technol. 2007, 39, 800-805. [CrossRef]

114. Sexton, L.; Lavin, S.; Byrne, G.; Kennedy, A. Laser cladding of aerospace materials. J. Mater. Process. Technol. 2002, 122, 63-68. [CrossRef]

115. Vilaro, T.; Colin, C.; Bartout, J.D.; Nazé, L.; Sennour, M. Microstructural and mechanical approaches of the selective laser melting process applied to a nickel-base superalloy. Mater. Sci. Eng. A 2012, 534, 446-451. [CrossRef]

116. Wang, Z.; Guan, K.; Gao, M.; Li, X.; Chen, X.; Zeng, X. The microstructure and mechanical properties of deposited-IN718 by selective laser melting. J. Alloys Compd. 2012, 513, 518-523. [CrossRef]

117. Abe, F.; Osakada, K.; Shiomi, M.; Uematsu, K.; Matsumoto, M. The manufacturing of hard tools from metallic powders by selective laser melting. J. Mater. Process. Technol. 2001, 111, 210-213. [CrossRef] 
118. Zhong, M.; Yang, L.; Liu, W.; Huang, T.; He, J. Laser rapid manufacturing of special pattern Inco 718 nickel-based alloy component. In Proceedings of the SPIE 5629, Photonics Asia, Beijing, China, 13 January 2005; pp. 59-66.

119. Kanagarajah, P.; Brenne, F.; Niendorf, T.; Maier, H.J. Inconel 939 processed by selective laser melting: Effect of microstructure and temperature on the mechanical properties under static and cyclic loading. Mater. Sci. Eng. A 2013, 588, 188-195. [CrossRef]

120. Baufeld, B. Mechanical properties of Inconel 718 parts manufactured by shaped metal deposition (SMD). J. Mater. Eng. Perform 2012, 21, 1416-1421. [CrossRef]

121. Li, J.; Wang, H.M.; Tang, H.B. Effect of heat treatment on microstructure and mechanical properties of laser melting deposited Ni-base superalloy Rene'41. Mater. Sci. Eng. A 2012, 550, 97-102. [CrossRef]

122. Acharya, R.; Bansal, R.; Gambone, J.J.; Kaplan, M.A.; Fuchs, G.E.; Rudawski, N.G.; Das, S. Additive manufacturing and characterization of René 80 superalloy processed through scanning laser epitaxy for turbine engine hot-section component repair. Adv. Eng. Mater. 2015, 17, 942-950. [CrossRef]

123. Harrison, N.J.; Todd, I.; Mumtaz, K. Reduction of micro-cracking in nickel superalloys processed by selective laser melting: A fundamental alloy design approach. Acta Mater. 2015, 94, 59-68. [CrossRef]

124. Wang, X.; Chou, Y.K. A method to estimate residual stress in metal parts made by selective laser melting. In Proceedings of the ASME 2015 International Mechanical Engineering Congress and Exposition, Houston, TX, USA, 13-19 November 2015.

125. Zhang, K.; Liu, W.J.; Shang, X.F. Characteristics of laser aided direct metal powder deposition process for nickel-based superalloy. Mater. Sci. Forum 2007, 534-536, 457-460. [CrossRef]

126. Sridharan, N.; Noakes, M.W.; Nycz, A.; Love, L.J.; Dehoff, R.R.; Babu, S.S. On the toughness scatter in low alloy C-Mn steel samples fabricated using wire arc additive manufacturing. Mater. Sci. Eng. A 2018, 713, 18-27. [CrossRef]

127. Zuback, J.S.; Palmer, T.A.; DebRoy, T. Additive manufacturing of functionally graded transition joints between ferritic and austenitic alloys. J. Alloys Compd. 2019, 770, 995-1003. [CrossRef]

128. Pinkerton, A.J.; Li, L. Direct additive laser manufacturing using gas-and water-atomised $\mathrm{H} 13$ tool steel powders. Int. J. Adv. Manuf. Technol. 2005, 25, 471-479. [CrossRef]

129. Hentschel, O.; Scheitler, C.; Fedorov, A.; Junker, D.; Gorunov, A.; Haimerl, A.; Merklein, M.; Schmidt, M. Experimental investigations of processing the high carbon cold-work tool steel 1.2358 by laser metal deposition for the additive manufacturing of cold forging tools. J. Laser Appl. 2017, 29, 022307. [CrossRef]

130. Mazur, M.; Brincat, P.; Leary, M.; Brandt, M. Numerical and experimental evaluation of a conformally cooled H13 steel injection mould manufactured with selective laser melting. Int. J. Adv. Manuf. Technol. 2017, 93, 881-900. [CrossRef]

131. Zhang, M.; Chen, C.; Qin, L.; Yan, K.; Cheng, G.; Jing, H.; Zou, T. Laser additive manufacturing of M2 high-speed steel. Mater. Sci. Technol. 2018, 34, 69-78. [CrossRef]

132. Chen, H.; Gu, D.; Dai, D.; Ma, C.; Xia, M. Microstructure and composition homogeneity, tensile property and underlying thermal physical mechanism of selective laser melting tool steel parts. Mater. Sci. Eng. A 2017, 682, 279-289. [CrossRef]

133. Sander, J.; Hufenbach, J.; Giebeler, L.; Bleckmann, M.; Eckert, J.; Kühn, U. Microstructure, mechanical behavior and wear properties of FeCrMoVC steel prepared by selective laser melting and casting. Scr. Mater. 2017, 126, 41-44. [CrossRef]

134. Fayazfar, H.; Salarian, M.; Rogalsky, A.; Sarker, D.; Russo, P.; Paserin, V.; Toyserkani, E. A critical review of powder-based additive manufacturing of ferrous alloys: Process parameters, microstructure and mechanical properties. Mater. Des. 2018, 144, 98-128. [CrossRef]

135. David, S.; Vitek, J.; Reed, R.; Hebble, T. Effect of Rapid Solidification on Stainless Steel Weld Metal Microstructures and Its Implications on the Schaeffler Diagram; Oak Ridge National Lab: Oak Ridge, TN, USA, 1987.

136. Amine, T.; Newkirk, J.W.; Liou, F. An investigation of the effect of direct metal deposition parameters on the characteristics of the deposited layers. Case Stud. Therm. Eng. 2014, 3, 21-34. [CrossRef]

137. Shah, K.; ul Haq, I.; Khan, A.; Shah, S.A.; Khan, M.; Pinkerton, A.J. Parametric study of development of Inconel-steel functionally graded materials by laser direct metal deposition. Mater. Des. 2014, 54, 531-538. [CrossRef] 
138. Rafi, H.K.; Pal, D.; Patil, N.; Starr, T.L.; Stucker, B.E. Microstructure and mechanical behavior of 17-4 precipitation hardenable steel processed by selective laser melting. J. Mater. Eng. Perform. 2014, 23, 4421-4428. [CrossRef]

139. Murr, L.E.; Martinez, E.; Hernandez, J.; Collins, S.; Amato, K.N.; Gaytan, S.M.; Shindo, P.W. Microstructures and properties of 17-4 PH stainless steel fabricated by selective laser melting. J. Mater. Res. Technol. 2012, 1, 167-177. [CrossRef]

140. Cheruvathur, S.; Lass, E.A.; Campbell, C.E. Additive manufacturing of 17-4 PH stainless steel: Post-processing heat treatment to achieve uniform reproducible microstructure. JOM 2016, 68, 930-942. [CrossRef]

141. Thijs, L.; Kempen, K.; Kruth, J.P.; Van Humbeeck, J. Fine-structured aluminium products with controllable texture by selective laser melting of pre-alloyed AlSi10Mg powder. Acta Mater. 2013, 61, 1809-1819. [CrossRef]

142. Dinda, G.P.; Dasgupta, A.K.; Bhattacharya, S.; Natu, H.; Dutta, B.; Mazumder, J. Microstructural characterization of laser-deposited Al 4047 alloy. Metall. Mater. Trans. A 2012, 44, 2233-2242. [CrossRef]

143. Kaya, H.; Çadırlı, E.; Böyük, U.; Maraşlı, N. Variation of microindentation hardness with solidification and microstructure parameters in the Al based alloys. Appl. Surf. Sci. 2008, 255, 3071-3078. [CrossRef]

144. Javidani, M.; Arreguin-Zavala, J.; Danovitch, J.; Tian, Y.; Brochu, M. Additive manufacturing of AlSi10Mg alloy using direct energy deposition: Microstructure and hardness characterization. J. Therm. Spray Technol. 2017, 26, 587-597. [CrossRef]

145. Yan, C.; Hao, L.; Hussein, A.; Young, P.; Huang, J.; Zhu, W. Microstructure and mechanical properties of aluminium alloy cellular lattice structures manufactured by direct metal laser sintering. Mater. Sci. Eng. A 2015, 628, 238-246. [CrossRef]

146. Aboulkhair, N.T.; Tuck, C.; Ashcroft, I.; Maskery, I.; Everitt, N.M. On the precipitation hardening of selective laser melted AlSi10Mg. Metall. Mater. Trans. A 2015, 46, 3337-3341. [CrossRef]

147. Li, W.; Li, S.; Liu, J.; Zhang, A.; Zhou, Y.; Wei, Q.; Yan, C.; Shi, Y. Effect of heat treatment on AlSi10Mg alloy fabricated by selective laser melting: Microstructure evolution, mechanical properties and fracture mechanism. Mater. Sci. Eng. A 2016, 663, 116-125. [CrossRef]

148. Kempen, K.; Thijs, L.; Van Humbeeck, J.; Kruth, J.-P. Processing AlSi10Mg by selective laser melting: Parameter optimisation and material characterisation. Mater. Sci. Technol. 2015, 31, 917-923. [CrossRef]

149. Rosenthal, I.; Shneck, R.; Stern, A. Heat treatment effect on the mechanical properties and fracture mechanism in AlSi10Mg fabricated by additive manufacturing selective laser melting process. Mater. Sci. Eng. A 2018, 729, 310-322. [CrossRef]

150. Tradowsky, U.; White, J.; Ward, R.; Read, N.; Reimers, W.; Attallah, M. Selective laser melting of AlSi10Mg: Influence of post-processing on the microstructural and tensile properties development. Mater. Des. 2016, 105, 212-222. [CrossRef]

151. Feng, K.; Chen, Y.; Deng, P.; Li, Y.; Zhao, H.; Lu, F.; Li, R.; Huang, J.; Li, Z. Improved high-temperature hardness and wear resistance of Inconel 625 coatings fabricated by laser cladding. J. Mater. Process. Technol. 2017, 243, 82-91. [CrossRef]

152. Foster, B.; Beese, A.; Keist, J.; McHale, E.; Palmer, T. Impact of interlayer dwell time on microstructure and mechanical properties of nickel and titanium alloys. Metall. Mater. Trans. A 2017, 48, 4411-4422. [CrossRef]

153. Hussein, N.; Segal, J.; McCartney, D.; Pashby, I. Microstructure formation in Waspaloy multilayer builds following direct metal deposition with laser and wire. Mater. Sci. Eng. A 2008, 497, 260-269. [CrossRef]

154. Jones, J.; Whittaker, M.; Buckingham, R.; Johnston, R.; Bache, M.; Clark, D. Microstructural characterisation of a nickel alloy processed via blown powder direct laser deposition (DLD). Mater. Des. 2017, 117, 47-57. [CrossRef]

155. Khayat, Z.; Palmer, T. Impact of iron composition on the properties of an additively manufactured solid solution strengthened nickel base alloy. Mater. Sci. Eng. A 2018, 718, 123-134. [CrossRef]

156. Zhang, F.; Levine, L.E.; Allen, A.J.; Stoudt, M.R.; Lindwall, G.; Lass, E.A.; Williams, M.E.; Idell, Y.; Campbell, C.E. Effect of heat treatment on the microstructural evolution of a nickel-based superalloy additive-manufactured by laser powder bed fusion. Acta Mater. 2018, 152, 200-214. [CrossRef]

157. Floreen, S.; Fuchs, G.E.; Yang, W.J. The metallurgy of alloy 625. Superalloys 1994, 718, 13-37.

158. Zhao, X.; Chen, J.; Lin, X.; Huang, W. Study on microstructure and mechanical properties of laser rapid forming Inconel 718. Mater. Sci. Eng. A 2008, 478, 119-124. [CrossRef] 
159. Zhong, C.; Gasser, A.; Kittel, J.; Wissenbach, K.; Poprawe, R. Improvement of material performance of Inconel 718 formed by high deposition-rate laser metal deposition. Mater. Des. 2016, 98, 128-134. [CrossRef]

160. Stevens, E.L.; Toman, J.; To, A.C.; Chmielus, M. Variation of hardness, microstructure and Laves phase distribution in direct laser deposited alloy 718 cuboids. Mater. Des. 2017, 119, 188-198. [CrossRef]

161. Tabernero, I.; Lamikiz, A.; Martínez, S.; Ukar, E.; Figueras, J. Evaluation of the mechanical properties of Inconel 718 components built by laser cladding. Int. J. Mach. Tools Manuf. 2011, 51, 465-470. [CrossRef]

162. Tucho, W.M.; Cuvillier, P.; Sjolyst-Kverneland, A.; Hansen, V. Microstructure and hardness studies of Inconel 718 manufactured by selective laser melting before and after solution heat treatment. Mater. Sci. Eng. A 2017, 689, 220-232. [CrossRef]

163. Zhang, D.; Niu, W.; Cao, X.; Liu, Z. Effect of standard heat treatment on the microstructure and mechanical properties of selective laser melting manufactured Inconel 718 superalloy. Mater. Sci. Eng. A 2015, 644, 32-40. [CrossRef]

164. Tillmann, W.; Schaak, C.; Nellesen, J.; Schaper, M.; Aydinöz, M.; Hoyer, K.-P. Hot isostatic pressing of IN718 components manufactured by selective laser melting. Addit. Manuf. 2017, 13, 93-102. [CrossRef]

165. Aydinöz, M.; Brenne, F.; Schaper, M.; Schaak, C.; Tillmann, W.; Nellesen, J.; Niendorf, T. On the microstructural and mechanical properties of post-treated additively manufactured Inconel 718 superalloy under quasi-static and cyclic loading. Mater. Sci. Eng. A 2016, 669, 246-258. [CrossRef]

166. Popovich, V.; Borisov, E.; Popovich, A.; Sufiiarov, V.S.; Masaylo, D.; Alzina, L. Impact of heat treatment on mechanical behaviour of Inconel 718 processed with tailored microstructure by selective laser melting. Mater. Des. 2017, 131, 12-22. [CrossRef]

167. Chlebus, E.; Gruber, K.; Kuźnicka, B.; Kurzac, J.; Kurzynowski, T. Effect of heat treatment on the microstructure and mechanical properties of Inconel 718 processed by selective laser melting. Mater. Sci. Eng. A 2015, 639, 647-655. [CrossRef]

168. Deng, D.; Peng, R.L.; Brodin, H.; Moverare, J. Microstructure and mechanical properties of Inconel 718 produced by selective laser melting: Sample orientation dependence and effects of post heat treatments. Mater. Sci. Eng. A 2017, 713, 294-306. [CrossRef]

169. Deng, D.; Moverare, J.; Peng, R.L.; Söderberg, H. Microstructure and anisotropic mechanical properties of EBM manufactured Inconel 718 and effects of post heat treatments. Mater. Sci. Eng. A 2017, 693, 151-163. [CrossRef]

170. Deng, D.; Saarimäki, J.; Söderberg, H.; Peng, R.; Brodin, H.; Moverare, J. Microstructural characterization of as-manufactured and heat treated electron beam melted Inconel 718. In Proceedings of the Materials Science and Technology, Salt Lake City, UT, USA, 23-27 October 2016; pp. 105-112.

171. Sames, W.J.; Unocic, K.A.; Helmreich, G.W.; Kirka, M.M.; Medina, F.; Dehoff, R.R.; Babu, S.S. Feasibility of in situ controlled heat treatment (ISHT) of Inconel 718 during electron beam melting additive manufacturing. Addit. Manuf. 2017, 13, 156-165. [CrossRef]

172. Schwab, H.; Bönisch, M.; Giebeler, L.; Gustmann, T.; Eckert, J.; Kuehn, U. Processing of Ti-5553 with improved mechanical properties via an in-situ heat treatment combining selective laser melting and substrate plate heating. Mater. Des. 2017, 130, 83-89. [CrossRef]

173. Dinda, G.; Song, L.; Mazumder, J. Fabrication of Ti-6Al-4V scaffolds by direct metal deposition. Metall. Mater. Trans. A 2008, 39, 2914-2922. [CrossRef]

174. Kelly, S.; Kampe, S. Microstructural evolution in laser-deposited multilayer Ti-6Al-4V builds: Part I. Microstructural characterization. Metall. Mater. Trans. A 2004, 35, 1861-1867. [CrossRef]

175. Hrabe, N.; Quinn, T. Effects of processing on microstructure and mechanical properties of a titanium alloy (Ti-6Al-4V) fabricated using electron beam melting (EBM), part 1: Distance from build plate and part size. Mater. Sci. Eng. A 2013, 573, 264-270. [CrossRef]

176. Galarraga, H.; Warren, R.J.; Lados, D.A.; Dehoff, R.R.; Kirka, M.M.; Nandwana, P. Effects of heat treatments on microstructure and properties of Ti-6Al-4V ELI alloy fabricated by electron beam melting (EBM). Mater. Sci. Eng. A 2017, 685, 417-428. [CrossRef]

177. Nassar, A.R.; Keist, J.S.; Reutzel, E.W.; Spurgeon, T.J. Intra-layer closed-loop control of build plan during directed energy additive manufacturing of Ti-6Al-4V. Addit. Manuf. 2015, 6, 39-52. [CrossRef]

178. Wang, P.; Tan, X.; Nai, M.L.S.; Tor, S.B.; Wei, J. Spatial and geometrical-based characterization of microstructure and microhardness for an electron beam melted Ti-6Al-4V component. Mater. Des. 2016, 95, 287-295. [CrossRef] 
179. Jamshidinia, M.; Atabaki, M.M.; Zahiri, M.; Kelly, S.; Sadek, A.; Kovacevic, R. Microstructural modification of Ti-6Al-4V by using an in-situ printed heat sink in electron beam melting ${ }^{\circledR}$ (EBM). J. Mater. Process. Technol. 2015, 226, 264-271. [CrossRef]

180. Hall, E. The deformation and ageing of mild steel: III discussion of results. Proc. Phys. Soc. Lond. B 1951, 64, 747-753. [CrossRef]

181. Petch, N.J. The cleavage strengh of polycrystals. J. Iron Steel Inst. 1953, 174, 25-28.

182. Petch, N. The fracture of metals. Prog. Metal Phys. 1954, 5, 1-52. [CrossRef]

183. Tabor, D. The Hardness of Metals; Oxford University Press Inc.: New York, NY, USA, 2000.

184. Cahoon, J.; Broughton, W.; Kutzak, A. The determination of yield strength from hardness measurements. Metall. Trans. 1971, 2, 1979-1983.

185. Tan, X.; Kok, Y.; Tan, Y.J.; Descoins, M.; Mangelinck, D.; Tor, S.B.; Leong, K.F.; Chua, C.K. Graded microstructure and mechanical properties of additive manufactured Ti-6Al-4V via electron beam melting. Acta Mater. 2015, 97, 1-16. [CrossRef]

186. Åkerfeldt, P.; Antti, M.-L.; Pederson, R. Influence of microstructure on mechanical properties of laser metal wire-deposited Ti-6Al-4V. Mater. Sci. Eng. A 2016, 674, 428-437. [CrossRef]

187. Palanivel, S.; Dutt, A.; Faierson, E.; Mishra, R. Spatially dependent properties in a laser additive manufactured Ti-6Al-4V component. Mater. Sci. Eng. A 2016, 654, 39-52. [CrossRef]

188. Ma, M.; Wang, Z.; Zeng, X. A comparison on metallurgical behaviors of 316L stainless steel by selective laser melting and laser cladding deposition. Mater. Sci. Eng. A 2017, 685, 265-273. [CrossRef]

189. Zhong, Y.; Liu, L.; Wikman, S.; Cui, D.; Shen, Z. Intragranular cellular segregation network structure strengthening 316L stainless steel prepared by selective laser melting. J. Nucl. Mater. 2016, 470, 170-178. [CrossRef]

190. Li, C.; Guo, Y.; Zhao, J. Interfacial phenomena and characteristics between the deposited material and substrate in selective laser melting Inconel 625. J. Mater. Process. Technol. 2017, 243, 269-281. [CrossRef]

191. Griffith, M.L.; Ensz, M.T.; Puskar, J.D.; Robino, C.V.; Brooks, J.A.; Philliber, J.A.; Smugeresky, J.E.; Hofmeister, W. Understanding the microstructure and properties of components fabricated by laser engineered net shaping (LENS). MRS Proc. 2000, 625, 9. [CrossRef]

192. Manfredi, D.; Ambrosio, E.; Calignano, F.; Krishnan, M.; Canali, R.; Biamino, S.; Pavese, M.; Atzeni, E.; Iuliano, L.; Fino, P. Direct metal laser sintering: An additive manufacturing technology ready to produce lightweight structural parts for robotic applications. Metall. Ital. 2013, 10, 15-24.

193. Read, N.; Wang, W.; Essa, K.; Attallah, M.M. Selective laser melting of AlSi10Mg alloy: Process optimisation and mechanical properties development. Mater. Des. 2015, 65, 417-424. [CrossRef]

194. Rosenthal, I.; Stern, A.; Frage, N. Strain rate sensitivity and fracture mechanism of AlSi10Mg parts produced by Selective Laser Melting. Mater. Sci. Eng. A 2017, 682, 509-517. [CrossRef]

195. Rosenthal, I.; Stern, A.; Frage, N. Microstructure and mechanical properties of AlSi10Mg parts produced by the laser beam additive manufacturing (AM) technology. Metall. Microstruct. Anal. 2014, 3, 448-453. [CrossRef]

196. Tang, M.; Pistorius, P.C. Oxides, porosity and fatigue performance of AlSi10Mg parts produced by selective laser melting. Int. J. Fatigue 2017, 94, 192-201. [CrossRef]

197. Vilaro, T.; Colin, C.; Bartout, J.D. As-fabricated and heat-treated microstructures of the Ti-6Al-4V alloy processed by selective laser melting. Metall. Mater. Trans. A 2011, 42, 3190-3199. [CrossRef]

198. Simonelli, M.; Tse, Y.Y.; Tuck, C. Effect of the build orientation on the mechanical properties and fracture modes of SLM Ti-6Al-4V. Mater. Sci. Eng. A 2014, 616,1-11. [CrossRef]

199. Zhao, X.; Li, S.; Zhang, M.; Liu, Y.; Sercombe, T.B.; Wang, S.; Hao, Y.; Yang, R.; Murr, L.E. Comparison of the microstructures and mechanical properties of Ti-6Al-4V fabricated by selective laser melting and electron beam melting. Mater. Des. 2016, 95, 21-31. [CrossRef]

200. Edwards, P.; O'conner, A.; Ramulu, M. Electron beam additive manufacturing of titanium components: Properties and performance. J. Manuf. Sci. Eng. 2013, 135, 061016. [CrossRef]

201. Zhai, Y.; Galarraga, H.; Lados, D.A. Microstructure evolution, tensile properties and fatigue damage mechanisms in Ti-6Al-4V alloys fabricated by two additive manufacturing techniques. Procedia Eng. 2015, 114, 658-666. [CrossRef]

202. Qiu, C.; Ravi, G.; Dance, C.; Ranson, A.; Dilworth, S.; Attallah, M.M. Fabrication of large Ti-6Al-4V structures by direct laser deposition. J. Alloys Compd. 2015, 629, 351-361. [CrossRef] 
203. Alcisto, J.; Enriquez, A.; Garcia, H.; Hinkson, S.; Steelman, T.; Silverman, E.; Valdovino, P.; Gigerenzer, H.; Foyos, J.; Ogren, J. Tensile properties and microstructures of laser-formed Ti-6Al-4V. J. Mater. Eng. Perform. 2011, 20, 203-212. [CrossRef]

204. Qiu, C.; Adkins, N.J.; Attallah, M.M. Microstructure and tensile properties of selectively laser-melted and of HIPed laser-melted Ti-6Al-4V. Mater. Sci. Eng. A 2013, 578, 230-239. [CrossRef]

205. Rafi, H.; Karthik, N.; Gong, H.; Starr, T.L.; Stucker, B.E. Microstructures and mechanical properties of Ti6Al4V parts fabricated by selective laser melting and electron beam melting. J. Mater. Eng. Perform. 2013, 22, 3872-3883. [CrossRef]

206. Kobryn, P.; Semiatin, S. Mechanical properties of laser-deposited Ti-6Al-4V. In Solid Freeform Fabrication Proceedings; The University of Texas: Austin, TX, USA, 2001; pp. 6-8.

207. Amsterdam, E.; Kool, G. High cycle fatigue of laser beam deposited Ti-6Al-4V and Inconel 718. In ICAF 2009, Bridging the Gap between Theory and Operational Practice; Springer: Berlin, Germany, 2009; pp. 1261-1274.

208. Brandl, E.; Leyens, C.; Palm, F. Mechanical properties of additive manufactured Ti-6Al-4V using wire and powder based processes. In Proceedings of the IOP Conference Series: Materials Science and Engineering; IOP Publishing: Bristol, UK, 2011.

209. Yao, B.; Ma, X.-L.; Lin, F.; Ge, W.-J. Microstructure and mechanical properties of Ti-6Al-4V components fabricated by laser micro cladding deposition. Rare Met. 2015, 34, 445-451. [CrossRef]

210. Wang, J.; Sun, Q.; Wang, H.; Liu, J.; Feng, J. Effect of location on microstructure and mechanical properties of additive layer manufactured Inconel 625 using gas tungsten arc welding. Mater. Sci. Eng. A 2016, 676, 395-405. [CrossRef]

211. Amato, K.; Hernandez, J.; Murr, L.; Martinez, E.; Gaytan, S.; Shindo, P.; Collins, S. Comparison of microstructures and properties for a Ni-base superalloy (alloy 625) fabricated by electron beam melting. J. Mater. Sci. Res. 2012, 1, 3. [CrossRef]

212. Qiu, C.; Adkins, N.J.; Attallah, M.M. Selective laser melting of Invar 36: Microstructure and properties. Acta Mater. 2016, 103, 382-395. [CrossRef]

213. Bauer, T.; Dawson, K.; Spierings, A.; Wegener, K. Microstructure and mechanical characterisation of SLM processed Haynes ${ }^{\circledR} 230^{\circledR}$. In Proceedings of the 26th Annual International Solid Freeform Fabrication Symposium, Austin, TX, USA, 10-12 August 2015; pp. 813-822.

214. Yadroitsev, I.; Thivillon, L.; Bertrand, P.; Smurov, I. Strategy of manufacturing components with designed internal structure by selective laser melting of metallic powder. Appl. Surf. Sci. 2007, 254, 980-983. [CrossRef]

215. Blackwell, P. The mechanical and microstructural characteristics of laser-deposited IN718. J. Mater. Process. Technol. 2005, 170, 240-246. [CrossRef]

216. Wang, Y.M.; Voisin, T.; McKeown, J.T.; Ye, J.; Calta, N.P.; Li, Z.; Zeng, Z.; Zhang, Y.; Chen, W.; Roehling, T.T. Additively manufactured hierarchical stainless steels with high strength and ductility. Nat. Mater. 2018, 17, 63-70. [CrossRef] [PubMed]

217. Parsa, A.B.; Ramsperger, M.; Kostka, A.; Somsen, C.; Körner, C.; Eggeler, G. Transmission electron microscopy of a CMSX-4 Ni-base superalloy produced by selective electron beam melting. Metals 2016, 6, 258. [CrossRef]

218. Divya, V.; Muñoz-Moreno, R.; Messé, O.; Barnard, J.; Baker, S.; Illston, T.; Stone, H.J. Microstructure of selective laser melted CM247LC nickel-based superalloy and its evolution through heat treatment. Mater. Charact. 2016, 114, 62-74. [CrossRef]

219. Akino, K.; Kakehi, K. Strengths and microstructure of SUS316L fabricated by selective laser melting. Mater. Trans. 2018, 59, 482-487. [CrossRef]

220. Morrow, B.M.; Lienert, T.J.; Knapp, C.M.; Sutton, J.O.; Brand, M.J.; Pacheco, R.M.; Livescu, V.; Carpenter, J.S.; Gray, G.T. Impact of defects in powder feedstock materials on microstructure of 304L and 316L stainless steel produced by additive manufacturing. Metall. Mater. Trans. A 2018, 49, 3637-3650. [CrossRef]

221. Qiu, Z.; Yao, C.; Feng, K.; Li, Z.; Chu, P.K. Cryogenic deformation mechanism of CrMnFeCoNi high-entropy alloy fabricated by laser additive manufacturing process. Int. J. Light. Mater. Manuf. 2018, 1, 33-39. [CrossRef]

222. Yoo, Y.S.J.; Book, T.A.; Sangid, M.D.; Kacher, J. Identifying strain localization and dislocation processes in fatigued Inconel 718 manufactured from selective laser melting. Mater. Sci. Eng. A 2018, 724, 444-451. [CrossRef] 
223. Martinez, E.; Murr, L.E.; Hernandez, J.; Pan, X.; Amato, K.; Frigola, P.; Terrazas, C.; Gaytan, S.; Rodriguez, E.; Medina, F. Microstructures of niobium components fabricated by electron beam melting. Metall. Microstruct. Anal. 2013, 2, 183-189. [CrossRef]

224. Hayes, B.J.; Martin, B.W.; Welk, B.; Kuhr, S.J.; Ales, T.K.; Brice, D.A.; Ghamarian, I.; Baker, A.H.; Haden, C.V.; Harlow, D.G. Predicting tensile properties of Ti-6Al-4V produced via directed energy deposition. Acta Mater. 2017, 133, 120-133. [CrossRef]

225. Pokharel, R.; Balogh, L.; Brown, D.; Clausen, B.; Gray, G.; Livescu, V.; Vogel, S.; Takajo, S. Signatures of the unique microstructure of additively manufactured steel observed via diffraction. Scr. Mater. 2018, 155, 16-20. [CrossRef]

226. Nandan, R.; DebRoy, T.; Bhadeshia, H.K.D.H. Recent advances in friction-stir welding-Process, weldment structure and properties. Prog. Mater. Sci. 2008, 53, 980-1023. [CrossRef]

227. Lancaster, J.F. Metallurgy of Welding, 6th ed.; Elsevier: Cambridge, MA, USA; London, UK, 1999.

228. Lienert, T.; Siewert, T.; Babu, S.; Acoff, V. ASM Handbook, Welding Fundamentals and Processes; ASM International: Materials Park, OH, USA, 2011; Volume 6A.

229. Zhang, L.; Wen, M.; Imade, M.; Fukuyama, S.; Yokogawa, K. Effect of nickel equivalent on hydrogen gas embrittlement of austenitic stainless steels based on type 316 at low temperatures. Acta Mater. 2008, 56, 3414-3421. [CrossRef]

230. Suzuki, H. Carbon equivalent and maximum hardness. Trans. Jpn Weld. Soc. 1984, 15, $25-33$.

231. Ito, Y.; Bessyo, K. Weldability Formula of High Strength Steels: Related to Heat-Affected Zone Cracking; International Institute of Welding: Villepinte, France, 1968; pp. 416-428.

232. Lienert, T.; Stellwag, W., Jr.; Grimmett, B.; Warke, R. Friction stir welding studies on mild steel. Weld. J. 2003, 82, 1-9. [CrossRef]

233. Nandan, R.; Roy, G.; Lienert, T.; Debroy, T. Three-dimensional heat and material flow during friction stir welding of mild steel. Acta Mater. 2007, 55, 883-895. [CrossRef]

234. Cui, L.; Fujii, H.; Tsuji, N.; Nogi, K. Friction stir welding of a high carbon steel. Scr. Mater. 2007, 56, 637-640. [CrossRef]

235. Khandkar, M.; Khan, J.A.; Reynolds, A.P. Prediction of temperature distribution and thermal history during friction stir welding: Input torque based model. Sci. Technol. Weld. Join. 2003, 8, 165-174. [CrossRef]

236. Hofmann, D.C.; Vecchio, K.S. Thermal history analysis of friction stir processed and submerged friction stir processed aluminum. Mater. Sci. Eng. A 2007, 465, 165-175. [CrossRef]

237. Kasuya, T.; Yurioka, N. Prediction of welding thermal history by a comprehensive solution. Weld J. 1993, 72, 107-115.

238. DebRoy, T.; David, S.A. Physical processes in fusion welding. Rev. Mod. Phys. 1995, 67, 85-112. [CrossRef]

239. Kenel, C.; Grolimund, D.; Li, X.; Panepucci, E.; Samson, V.A.; Sanchez, D.F.; Marone, F.; Leinenbach, C. In situ investigation of phase transformations in Ti-6Al-4V under additive manufacturing conditions combining laser melting and high-speed micro-X-ray diffraction. Sci. Rep. 2017, 7, 16358. [CrossRef] [PubMed]

240. Zheng, B.; Zhou, Y.; Smugeresky, J.E.; Schoenung, J.M.; Lavernia, E.J. Thermal Behavior and Microstructural Evolution during Laser Deposition with Laser-Engineered Net Shaping: Part I. Numerical Calculations. Metall. Mater. Trans. A 2008, 39, 2228-2236. [CrossRef]

241. Hooper, P.A. Melt pool temperature and cooling rates in laser powder bed fusion. Addit. Manuf. 2018, 22, 548-559. [CrossRef]

242. Arora, A.; DebRoy, T.; Bhadeshia, H. Back-of-the-envelope calculations in friction stir welding-velocities, peak temperature, torque and hardness. Acta Mater. 2011, 59, 2020-2028. [CrossRef]

(C) 2018 by the authors. Licensee MDPI, Basel, Switzerland. This article is an open access article distributed under the terms and conditions of the Creative Commons Attribution (CC BY) license (http://creativecommons.org/licenses/by/4.0/). 